\title{
Almost 25 years of chromatographic and spectroscopic analytical method development for petroleum hydrocarbons analysis in soil and sediment: state-of-the-art, progress and trends
}

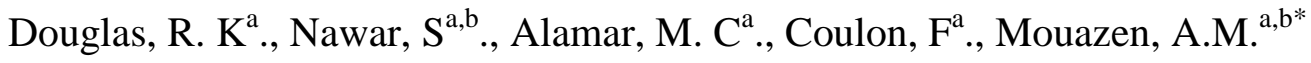

${ }^{a}$ School of Water, Energy and Environment, Cranfield University, Cranfield, MK43 0AL, UK.

${ }^{\mathrm{b}}$ Department of Soil Management, Ghent University, Coupure 653, 9000 Gent, Belgium

E-mail of corresponding authors: abdul.mouazen@ugent.be; f.coulon@cranfield.ac.uk

\begin{abstract}
This review provides a critical insight into the selection of chromatographic and spectroscopic techniques for semi-quantitative and quantitative detection of petroleum hydrocarbons in soil and sediment matrices. Advantages and limitations of both field screening and laboratory-based techniques are discussed and recent advances in chemometrics to extract maximum information from a sample by using the optimal preprocessing and data mining techniques are presented. An integrated analytical framework based on spectroscopic techniques integration and data fusion for the rapid measurement and detection of on-site petroleum hydrocarbons is proposed. Furthermore, factors influencing petroleum hydrocarbons analysis in contaminated samples are discussed and recommendations on how to reduce their influence provided.
\end{abstract}

Keywords: Analytical techniques, multi-sensor and data fusion, contaminated soil, petroleum hydrocarbons. 


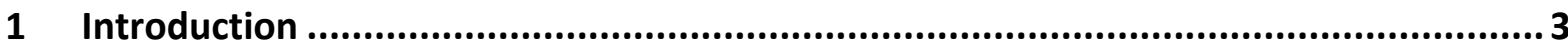

2 Overview of analytical techniques for petroleum hydrocarbons detection.................6 6

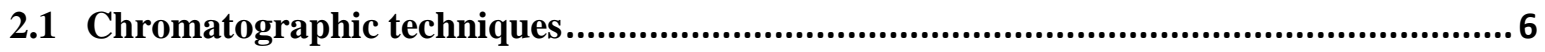

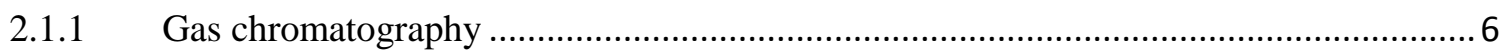

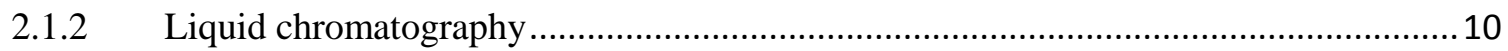

2.1.3 Portable/Field Gas Chromatography ……........................................................... 12

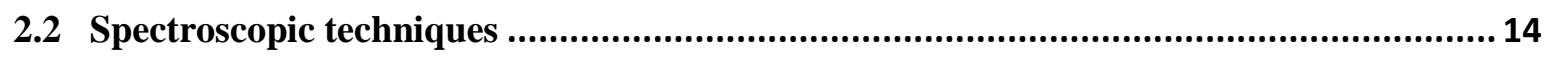

2.2.1 X-ray fluorescence spectroscopy (XRFS) ……......................................................... 14

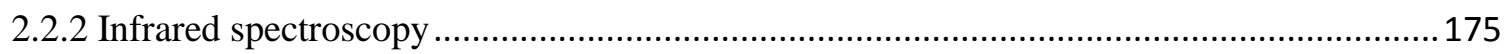

2.2.3 Visible and near-infrared (Vis-NIR) spectroscopy ...................................................... 17

2.2.4. Mid-infrared (MIR) spectroscopy .................................... Error! Bookmark not defined.2

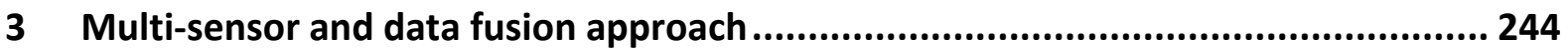

4 Decision making in selecting a detection techniques: advantages and limitations ..... 25

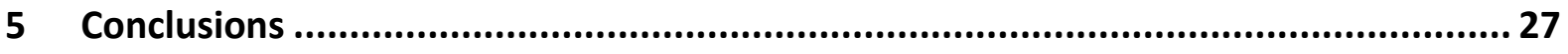




\section{Introduction}

Land contamination from either poor historical industrial practices or incidents is a widespread and well-recognized environmental issue. In the EU alone, ca. 342,000 sites are affected by industrial activity leading to soil contamination (Van Liedekerke et al., 2014). Petroleum hydrocarbons (PHC) are common contaminants found in the environment. PHC encompass hundreds of various aromatic and aliphatic compounds as well as traces of heterocyclic compounds (containing sulphur, nitrogen, oxygen), which are well-known environmental contaminants (Coulon et al., 2010; Cozzolino, 2015). When the focus is about PHC, the difference between the terms PHC and total petroleum hydrocarbons (TPH) should be noted. PHC typically refer to the hydrogen and carbon containing compounds that originate from crude oil, whereas $\mathrm{TPH}$ refer to the measurable amount of petroleum-based hydrocarbons in an environmental matrix and, therefore, to the actual results obtained by sampling and chemical analysis (Coulon and $\mathrm{Wu}, 2017)$. Thus, TPH is a method-defined term and therefore the estimates of TPH concentrations will vary depending on the analytical method used to measure it. Historically this has been a significant source of inconsistency, as laboratories have different interpretations of the term TPH.

Over the last two decades, numerous field and laboratory techniques have been developed for the identification and quantification of TPH and polycyclic aromatic hydrocarbons (PAHs), as well as for the fractionation and quantification of aliphatic and aromatic hydrocarbons (Coulon and $\mathrm{Wu}, 2017$; Li et al., 2015; Forester et al., 2013; Schwartz et al., 2012; Brassington et al., 2010). Field-based spectroscopic techniques offer rapid, non-destructive and cost-effective means of defining levels and distribution of PHC on-site before undertaking more costly and lengthy laboratory-based chemical analysis. In addition, they can provide real-time monitoring data and, therefore, be useful for initial site assessment and inform future sampling campaign for detailed risk assessment of the contaminated sites. 
However, one drawback of these field-based techniques is that they often fail to determine and quantify the entire range of PHC in soil or sediment. Therefore, choosing which technique to use is an important process to enable effective site investigation (Gałuszka et al., 2015); equally important it is to understand the type and quality of data generated (i.e., qualitative, semi-quantitative and quantitative). Moreover, their interpretation needs to be carefully evaluated before conclusions on a best technique to adopt can be drawn.

In contrast, laboratory techniques provide accurate analytical measurement and determination of hydrocarbons. They are, however, comparatively more expensive and require extra time for sample extraction and analysis (Forrester et al., 2013). Laboratory-based techniques include gas chromatography with flame ionization detector (GC-FID), GC coupled with mass spectrometry (GC-MS) or two-dimensional gas chromatography with FID (GC×GC-FID), GC $\times$ GC coupled with time-of-flight mass spectrometry (GC $\times$ GC/TOFMS), GC interfaced with quadrupole time-of-flight (GC-QTOF) tandem mass spectrometry. Raman spectroscopy (RS), infrared spectroscopy (IRS) and high performance liquid chromatography (HPLC) coupled with either fluorescence or ultraviolet visible detection. Among these techniques, GC-FID and GC-MS are the most common choices for PHC fingerprinting analysis of environmental matrices. The particular advantage of GC-FID is that the quantitative response of the FID is approximately the same for equal weights of any hydrocarbon, so that in a first approximation, relative peak areas can be used directly for the determination of weight percentage values (Malley et al. 1999). Similarly, GC-MS is used for more comprehensive analysis due to its ability to resolve and specify a broad range of hydrocarbon compounds, including hydrocarbon biomarkers (Wang and Fingas, 1995; Barnes, 2009; Brassington et al., 2010; Coulon and $\mathrm{Wu}, 2017)$. While GC-MS and GC-FID are mature techniques with excellent performance, there are still fascinating new developments such as $\mathrm{GC} \times \mathrm{GC}, \mathrm{GC} \times \mathrm{GC}$ Time-of-flight mass spectrometry (TOF-MS), and GC-QTOF amongst others. 
Given the relative difficulty (and expense) of the GC techniques described above, there has recently been considerable efforts in finding satisfactory rapid measurement techniques to be used in the field. Optical methods such as visible and near-infrared spectroscopy (vis-NIRS), mid-infrared (MIR) and X-ray fluorescence (XRF) spectroscopy have been identified as suitable techniques for implementation in the laboratory and/or the field (Chakraborty et al., 2010; Okparanma and Mouazen, 2012). Portable vis-NIR spectrophotometers have been one of the most popular instruments used for on-site determination of a wide range of analytes since the 1990s (McMahon, 2007). They offer quick, cost-effective measurement and do not require sample preparation (McCarty et al., 2002; Viscarra Rossel et al., 2006; He et al., 2007). Likewise, MIR spectroscopy has been used for the detection of PHC (Horta et al., 2015). Although this technology is field-deployable, soil type and moisture can affect the measurement accuracy. Field portable X-ray fluorescence (PXRF) spectrometers also offer many advantages over traditional techniques including speed, portability, wide dynamic range of elemental quantification, little/no need for sample preparation and simplicity (Weindorf et al., 2014).

Research into multi-sensor and data fusion for the determination of soil properties has made significant advances (O'Rourke et al., 2016; Wang et al., 2015) during the last decade, yet it is still young for PHCs in environmental samples. Research needs to embrace combination of techniques for PHCs that are portable, rapid, and requires no consumables, making it attractive and economic. A multi-sensor and data fusion approach is the next step that may open new windows for new applications, where the performance of the current spectroscopic methods can be maximized (Mouazen et al., 2016). To the best of our knowledge, there is no study yet reviewing and/or demonstrating the potential of field-portable multi-sensor and data fusion for the analysis of PHC in contaminated soil and sediment. 
This paper provides (i) a critical review of the main laboratory and field chromatographic and spectroscopic techniques used in the determination of PHCs and fractions; (ii) insights into the advantages and limitations of both techniques; and (iii) discussion on the potential of optical, field-portable integrated framework of XRF+MIR, vis-NIR+MIR or XFR+visNIRS+MIR for timely, cost-effective and more accurate analysis of PHCs in soil and sediment.

\section{Overview of analytical techniques for petroleum hydrocarbons detection}

PHCs are separated into saturated and aromatic fractions; both fractions consist of highly complex mixture of hydrocarbons. The saturated fraction is composed of n-alkanes, branched alkanes and cycloalkanes and may also contain unsaturated hydrocarbons (alkenes). The aromatic fraction contains mainly compounds with two or more fused aromatic rings with or without a degree of alkylation. It may also contain polar non-hydrocarbons such as thiophenes, dibenzothiophenes and the oxygen-analogous aromatic heterocycles due to similar physico-chemical properties and therefore they are difficult to separate from the aromatic hydrocarbons. A number of analytical techniques have been developed for the quantification of PHCs in soil samples. This review, however, focuses only on chromatographic and spectroscopic techniques (Table 1).

(Table. 1)

\subsection{Chromatographic techniques}

\subsubsection{Gas chromatography}

Most environmentally important hydrocarbons are relatively volatile and thermally stable. Therefore, gas chromatographic techniques requiring the target compounds to be vaporised without destruction, have been established as the most important method for hydrocarbon separation. Gas chromatography (GC) is perhaps the most robust analytical instrument used 
for determining the structural composition and quantification of volatile mixtures such as $\mathrm{TPH}$ in environmental samples. The ability to couple highly sensitive detectors such as the flame ionization detector (FID) and mass spectrometry (MS) makes it a choice for highly sensitive petroleum analysis.

The principles are common to all chromatographic separation methods: the analytes of interest carried along by a mobile phase interact with a stationary phase and separate through these interactions. The separated analytes are detected as they elute. In GC, the mobile phase is helium the carrier gas. The stationary phase is typically a thin film chemically bonded to a narrow-bore capillary column. Most common coating used in hydrocarbon analysis are nonpolar stationary phases such as polydimethylsiloxanes or slightly more polar polysiloxanes in which a certain proportion (e.g., 5\%) the methyl groups is substituted by phenyl groups. Important physical parameters influencing the separation characteristics of the analytical columns include the column length, its inner diameter and the film thickness of the stationary phase.

Flame ionization detection (FID) is the most used in gas chromatography than any other method for signal detection. This is because the burning of carbon compounds produces ions that will be detected by the FID. The success of FID resides mainly in its very low noise level, linear response over a very wide concentration range, and its sensitivity and its response varies very little with factors such as detector temperature and carrier gas flow rate (Weisman, 1998). However the FID response depends on the number of ions produced by a compound. Since this varies considerably between hydrocarbon classes, FID response factors vary accordingly (Karasek and Clement, 2003). The ability of a chromatographic method to successfully separate, identify and quantify species is determined by many factors as critically reviewed by Hibbert (2012). For example the observed GC retention times mainly depend on the temperature, flow rate and column length settings and, therefore, they are not 
ideal parameters for identification purposes. Instead, retention index (RI) also known as Kovats retention index is used to convert retention times into system-independent constants (Marriot et al., 2012; Song et al., 2002). Temperature oven optimisation may also be required to resolve specific target compounds such as diastereomers with very similar physical properties. While a comprehensive listing of all factors and solutions for optimising GC is beyond the scope of this review, there are several references on the gas chromatographic theory and principles, instrumentations and applications available (see Dettmer-Wilde and Engewald (2014)).

Gas chromatography mass spectrometry (GC-MS) is a hyphenated analytical technique commonly used for environmental analysis due its specific and distinct monitoring capacity, especially when applied in the selective ion mode (Wang and Fingas, 1995; Brassington et al., 2010; Yang et al., 2015). The identification and characterization of petroleum compounds by GC-MS is achieved by comparing retention time and a query mass spectrum with reference mass spectra in a library via spectrum matching. Versions of the NIST library, currently containing over 276,000 reference spectra, and search algorithms are available from all major MS manufacturers (Yang et al., 2015). Such method has been used to assess the PAHs in tar-contaminated soils (Lorenzi et al., 2010) and monitor bioremediation of PAHcontaminated soil via in-vessel composting using fresh organic waste (Zhang et al., 2011).

The MS analyzer can serve as both a selective and universal detector in the analysis of hydrocarbons. Electron impact at $70 \mathrm{eV}$ is the most common mode, whereby an electron is stripped from the parent molecule (M) generating an $\mathrm{M}+$ ion, which may undergo further fragmentation. Most hydrocarbons will only have one charge, so the mass is equivalent to the $\mathrm{m} / \mathrm{z}$ ratio. Other methods, such as chemical, supersonic, and field ionization, are amenable to interfacing with gas chromatography and are soft ionization techniques that preferentially yield parent ions with limited fragmentation (Giri et al., 2017). 
Recent studies also demonstrated that the performance compound identification depends on multiple factors including the mass spectrum library, spectral similarity measure and weight factors. They further showed that the compound identification based on mass spectra only has limited accuracy and the high accuracy compound identification can be achieved by incorporating compound separation information into mass spectrum matching. Since retention time in $\mathrm{GC}$ depends on experiment condition dependent, combination of retention index with mass spectrum is becoming more widely used (Marriot et al., 2012).

In comprehensive two-dimensional gas chromatography $(\mathrm{GC} \times \mathrm{GC})$, the entire sample is subjected to two distinct analytical separations resulting in an enhanced separating capacity most useful for the characterization of complex mixtures of organic compounds ( $\mathrm{Li}$ et al., 2015). Additionally, it has been reported that combining two-dimensional gas chromatography (GC $\times \mathrm{GC})$ and TOF-MS can facilitates the identification of compounds by providing adequate spectrum acquisition speed, producing robust structural information without mass spectral skewing across the chromatographic peak (Tran et al. 2010; Li et al., 2015). This system has a high resolution of many co-elution substances including tricyclic and pentacyclic terpanes (Avila et al., 2010; Tran et al. 2010). Li et al. (2015) also used GC $\times$ GC-TOF-MS with a reverse-phase column system (one-dimensional polar column coupled with two-dimensional nonpolar column) in addition to the normal-phase system (one-dimensional nonpolar column coupled with two-dimensional polar column) to separate and identify components of crude oils. While the normal phase system is useful for separating hydrocarbons, especially high molecular weight compounds between $\mathrm{C}_{25}-\mathrm{C}_{35}$ (Tissot and Welte, 1984), the reverse-phase system allows a greater separation for medium-low molecular weight cycloalkanes, which are normally very difficult to separate from aromatic hydrocarbons in normal phase system ( $\mathrm{Li}$ et al., 2015). It also allows the identification of suitable biomarkers including steranes and terpanes (Li et al., 2015). 
Both high-temperature and comprehensive two-dimensional GC provide relatively recent methodological advances for PHC analysis offering greater resolution and characterisation of complex mixtures of hydrocarbons. Specifically, high-temperature GC is a key technique in extending the molecular application range of gas chromatography.

Simulated distillation (SimDis) GC utilises fused silica column that considerably lowers the elution temperature of the analytes, which results in a decrease in the final oven temperature while ensuring a complete separation of the mixture (Boczkaj et al., 2011). This removes the chance of breakdown of less thermally stable mixture components and bleeding of the stationary phase thereby improving the detector signal. SimDis GC method permits the characterization of the effective carbon number distribution of the constituent classes of soil extracts by a non-polar GC as a surrogate distillation column, where fractions are distilled using linear temperature profile (Pollard et al., 2004). SimDis GC of various fractions of soil extracts were achieved (Pollard et al., 2004) with a modified American Society for Testing and Materials (ASTM) method D2887-89 (ASTM, 1992). The authors performed SimDis GC using a Hewlett-Packard 5890 GC equipped with an on-column temperature controlled injector, an aluminium clad and Quadrex column coated with phenyl silicone. An oven temperature programmed at $55-420^{\circ} \mathrm{C}$ was employed at a linear rate of $10^{\circ} \mathrm{C} / \mathrm{min}$.

\subsubsection{Liquid chromatography}

Hydrocarbon analysis can be performed by various liquid chromatography techniques, such as thin layer chromatography (TLC), open-column liquid chromatography (OCLC), medium pressure liquid chromatography (MPLC) and high-performance liquid chromatography (HPLC) (Barman et al., 2000; Pan et al., 2013). Due to the nonpolar nature of the PHC normal-phase LC is commonly used (Chibwe et al., 2017). Accordingly, solvents or solvent 
systems used for isocratic or gradient elution are typically nonpolar in normal phase separations. A broad variety of detectors can be used for PHC, including spectroscopic (UVVis, fluorescence, infrared), bulk property (refractive index, evaporative light-scattering, dielectric constant, flame-ionization), mass spectrometric and element specific detectors. UVVis detection provides excellent sensitivity for aromatic but is not applicable to saturated hydrocarbons. The utility of common atmospheric pressure ionization interfaces used for online coupling of LC and mass spectrometry in the analysis of volatile and/or nonpolar compounds is rather limited. TLC coupled to flame-ionization detection (FID) is an important compound group screening method in hydrocarbon analysis (Cavanagh et al., 1995). TLCFID is a promising method for analysing oil fractions including aromatics. It has been used to separate solvent-extractable petroleum organics on silica-coated quartz rods into paraffins, aromatics and polar constituents (Dunn et al., 2000). Napolitano et al., (1998) also used TLCFID as a quick way of measuring PHCs in soils.

HPLC separation is limited to aromatics but has a high sensitivity (Pan et al 2013). Greater interference due to co-elution is therefore more likely to occur for HPLC separation compared to GC separation. This will be especially marked in a heavily hydrocarbon contaminated environmental sample where there will be a large number of different PAHs (Coulon et al., 2012). HPLC techniques are applied much less, for oil-fingerprinting analysis in comparison to GC methods (Yang et al., 2015). The major disadvantage of HPLC applications for quantification is the lack of universal detector, which yields same response for all class of chemical constituents (Sarowha et al., 1997). 


\subsubsection{Portable/Field Gas Chromatography}

The quest to cut down the expensive delays associated to laboratory-based GCs triggered portable designs of GCs. For instance, field gas chromatographs (FGCs), portable GC FROG 4000, and HAPSITE chemical identification system, among others are available. The FGCs measure constituent-definite analysis of soil-gas, soil, and water samples for volatile and semi-volatile hydrocarbons. FGCs are the only field measuring techniques for methyl tertiary butyl ether (MTBE) and they are of two types, namely, (person)-portable gas chromatographs (PGCs) and transportable gas chromatographs (TGCs) (EPA, 1997). PGCs are portable analytical devices used for hydrocarbons analysis. The PGCs possesses in-house batteries and carrier gas provider thus making the equipment portable. However, there is limited power supply due to the features (EPA, 1997). Portable gas chromatographs such as Portable FROG 4000 and Portable-GC-TMS weighs $2.2 \mathrm{~kg}$ and $4.5 \mathrm{~kg}$, respectively (Koshy and Sudhakar, 2013). However, "fit for purpose" lightweight cylinders to supply the carrier gas have been recommended; thus, it tends to attract high cost (Deeks et al., 2014). Portable GC FROG 4000 has been applied onsite for analysing volatile organic compounds (VOCs) in soil, air and water in ppm and sub ppm in less than 5 min for benzene, toluene, ethylbenzene and xylene (BTEX) (California Geotechnical Services, 2016). With benchtop quality analysis, GC FROG 4000 satisfy the needs of various applications including site characterization and assessment, soil characterization, groundwater monitoring, Brownfield remediation, Superfund clean-up and leak detection (California Geotechnical Services, 2016).

HAPSITE is the only field-portable GC-MS for on-site detection, recognition and quantification of VOCs, toxic industrial chemicals (TICs) and chemical warfare agents (CWAs) [low molecular weight synthetic compounds that act very fast and are deadly at low concentration levels] (www.inficon.com). HAPSITE has the ability to detect and identify VOCs in parts per million to parts per trillion range. The results (obtained in minutes) from 
HAPSITE may be useful for the investigation of problems triggered by a very low concentration of contaminants that are essential for critical decision-making affecting human life, health and safety. Operators of HAPSITE require minimal training (www.inficon.com). In conclusion, PGCs are field deployable and have less analysis run time. However, the method is not sensitive to many aliphatic compounds. HAPSITE measures very low contaminant's concentration and is timely. HAPSITE results are useful for health and safety decision making. In addition, with European Standard ENISO 22155:2016, it is possible to measure volatile aromatic and halogenated hydrocarbons and selected aliphatic ethers in soil. ENISO 22155:2016 requires static headspace method for quantitative gas chromatographic measurements, and it is useful for all soil types. The limit of detection (LOD) depends upon the detection system used and the quality of the solvent (methanol grade) used for the extraction. In this method, the following LOD applies (expressed based on dry matter): typical LOD using GC-FID for volatile aromatic hydrocarbons is $0.2 \mathrm{mg} / \mathrm{kg}$, aliphatic ethers such as methyl tert-butyl ether (MTBE) and tert-amyl methyl ether (TAME) is $0.5 \mathrm{mg} / \mathrm{kg}$. Using GC-electron capture detection, the typical LOD for volatile halogenated hydrocarbons is 0.01 to $0.2 \mathrm{mg} / \mathrm{kg}$ (ENISO 22155:2016). However, there remain many obstacles to overcome so that a greater community of users can adequately and economically deploy this type of instrumentation. This instrumentation is still bulky (vacuum system, gas canister etc.), power hungry, and somewhat fragile.

TGCs are not person-portable (but transportable - heavy weight) and they separate well the constituents due to the presence of long capillary columns. TGCs can generate results comparable to laboratory quality (Koshy and Sudhakar, 2013). They accurately identify and quantify the constituents in samples.

Truly most common applications of field GC are the measurement of VOCs in air, such as BTEX, and chemical-warfare agents. Due to the huge demand for rapid, on-site analysis of 
environmental contaminants, there is a need for technological advancement in developing the already existing fast scanning techniques including GC×GC/TOFMS, and GC-QTOF tandem mass spectrometry to achieve analysis of contaminants in the field. This would help real-time decisions and cost-effective solutions to the challenges encountered during site investigation. The use and demand for field GC-MS will continue to grow as these instruments are miniaturized and performance remains at lab-quality. As more of these newer instruments enter the market, the costs will invariably drop to refuel the instrument development cycle.

\subsection{Spectroscopic techniques}

A number of spectroscopic techniques exist for the analysis of environmental contaminants (e.g., TPHs and PAHs). However, this current study focuses on the applications of XRFS, IR, vis-NIRS and MIRS for the analyses of TPH, PAH or both.

\subsubsection{X-ray fluorescence spectroscopy (XRFS)}

XRFS is a well-known laboratory technique (Hou et al., 2004). XRF functions on the principle that electrons embedded in the inner energy shell of an atom cleave from their shell upon excitation by X-rays. Electrons from the elevated, external, energy shells due to the discharge of excess energy in the form of an X-ray photon, occupy nearly instantly the voids in the inner shells created by electrons being cleaved following the X-ray excitation (Weindorf et al., 2014). The associated wavelength of the XRF thus depends on the energy level of the electrons in the interior shells. Moreover, the fluorescence emission is dependent upon the atom's principal inner shell electrons taking part in excitation (Hou et al., 2004). Consequently, XRF detectors can measure the X-ray spectrum of any element, though they cannot efficiently measure elements with atomic numbers less than twelve (Horta et al., 2015). Hou et al. (2004) have previously reported the application of XRF for the analyses of PHCs in soil, water and liquid samples. With recent technological improvements, portable 
XRF spectrometers have now become available; they have been used to rapidly measure soil contaminants (with minimal sample preparation required) and offer a number of strengths relative to traditional laboratory-based methods (Horta et al., 2015). Both, wavelength dispersive $\mathrm{x}$-ray fluorescence (WD-XRF) or energy dispersive $\mathrm{x}$-ray fluorescence (ED-XRF) are commonly used as portable XRF instruments. The former is of higher resolution with fewer spectral overlaps and lower background intensities, but it is more expensive and prone to error than the latter. The ED-XRF analyser is designed to detect a group of elements all at once. One of the most advantages of XRF as a portable handheld device "gun-shaped meter" is that it can be taken to the field for analysis of soils in situ. The time of scanning is short, typically ranging between 60 to 90s. In addition, portable XRF instruments are operated by rechargeable $\mathrm{Li}$-ion batteries that enable $6-12 \mathrm{~h}$ field measurements; thus, requiring no conventional electrical power supply on site. Indeed, XRF has been reported to be an accurate, non-destructive, and cost-effective method (Ulmanu et al., 2011); its use in environmental surveying has also been described (Hou et al., 2004).

Aside from its ability to mainly quantify and screen soil nutrients, the XRF technique has been used in combination with vis-NIR diffuse reflectance spectroscopy (DRS) to produce an optimised model for the swift measurement of soil HCs in Texas (Chakraborty et al., 2015). The authors concluded that the synergistic use of vis-NIR and XRF technique is viable for a quick and cost-effective quantification of petroleum contamination in soil.

\subsubsection{Infrared spectroscopy}

The electromagnetic spectrum of IRS consists of three regions i.e., near infrared (14000 $4000 \mathrm{~cm}^{-1}$ or $\left.750-2500 \mathrm{~nm}\right)$, mid-infrared $\left(4000-400 \mathrm{~cm}^{-1}\right.$ or $\left.2500-25000 \mathrm{~nm}\right)$ and far infrared $\left(400-10 \mathrm{~cm}^{-1}\right.$ or $\left.25000-1000000 \mathrm{~nm}\right)$. In this section the application of IRS (lab-based), visNIR and MIR techniques for the analysis of PHCs will be discussed separately. 
IRS is generally applied for the measurement of organic compounds in soil, though some inorganic compounds may equally produce infrared signals (Horta et al., 2015). IR uses the stretching and bending modes of vibrations linked with molecules when they absorb energy in the infrared region of the electromagnetic spectrum for property clarification (Weisman, 1998). In this method, spectra of hydrocarbon compounds are generated from the carbonhydrogen (e.g., $\mathrm{C}-\mathrm{H}$ ) linkages of saturated $\mathrm{CH}_{2}$ and terminal $\mathrm{CH}_{3}$ functional chemical groups, which are observed within the MIR spectral range of $3000-2900 \mathrm{~cm}^{-1}$ or a particular waveband of $2930 \mathrm{~cm}^{-1}$ (Weisman, 1998). To start with, samples are extracted using an eluting solvent with no C-H bonds. Prior to IR analysis, the eluate is passed through silica gel to eliminate biogenic polar compounds. Subsequently, the absorbance of the eluate is measured at the particular waveband, and further compared with a calibration curve made using petroleum hydrocarbon standards at known concentrations (Weisman, 1998).

IRS techniques were often employed for the detection of TPH in soils before the development of GC-based techniques (Current and Tilotta, 1997) due to its official acceptance by EPA (EPA method 418.1) (EPA, 1978) and International Organization for Standardization (ISO) (e.g. ISO/TR 11046) (Becker et al., 2002). Currently, the use of IRS-based systems is scanty due to the ban of Freon (1,1,2-trichlorotrifluoethane, CFE) for solvent extraction (Forrester et al., 2010; Weisman, 1998; Becker et al., 2002). Furthermore, the ISO for France has replaced ISO/TR 11046 with ISO/DIS 16703, which suggests using GC-FID detector instead of IRS technique to follow extraction using non-halogenated solvent (ENISO16703:2011). In addition, the technique has been reported to be insensitive to unsaturated fractions of weathered hydrocarbons, showing no measurable adsorption bands at screening wavelength (Whittaker et al., 1995; Fan et al., 1994). IRS methods face with problems of interference (positive and negative); however, multivariate calibration annuls it. Sample porosity also affects IRS signal intensity (Forrester et al., 2010). Nevertheless, IRS methods provide 
quantitative responses, by employing calibrated standards with the analyser being positioned at the desired wavelength. Via a programmed calibration, concentration in parts per million (ppm) of the whole hydrocarbon can be determined (Deeks et al. 2014). IR-based techniques are simple, fast, and cost-effective with LOD of $\sim 10 \mathrm{mg} / \mathrm{kg}$ in soil, though they are not portable for field measurement (Weisman, 1998).

\subsubsection{Visible and near-infrared (Vis-NIR) spectroscopy}

The principle of near infrared (NIR) spectroscopy is based on the absorption of energy (generated by a light source) by substances, which result from fundamental vibrations of molecules that take place in the MIR range. Fundamental vibrations are of different modes but not limited to the stretching and bending of bonds that entails $\mathrm{C}-\mathrm{H}, \mathrm{O}-\mathrm{H}, \mathrm{N}-\mathrm{H}$ and $\mathrm{S}-\mathrm{H}$ chemical bonds (Osborne et al., 1993). However, in the NIR range (780 - $2500 \mathrm{~nm})$ overtones and combinations of fundamental vibration are generated (Kuang et al., 2012). These are broad waveband signatures and require advanced chemometrics or machine learning tools to extract useful quantitative and qualitative information. In the visible (vis) range (400-780 nm), absorption bands related to soil colour are due to electron excitations, which assist the measurement of soil organic matter content and moisture content (Kuang et al., 2012; Viscarra Rossel et al., 2009). However, vis-NIR spectroscopy is not appropriate for the elucidation of chemical structures (Pasquini, 2003) and advanced chemometric methods must be used to achieve more robust recognition and quantitative models (Pasquini, 2003).

In the late 1980s, the spectral characteristics of hydrocarbons were first documented (Cloutis, 1989). The spectra of hydrocarbons emanated primarily from either a combination or overtones of fundamental vibrations in the MIR region e.g., $\mathrm{C}-\mathrm{H}$ stretching modes of aliphatic $\mathrm{CH}_{2}$ and terminal $\mathrm{CH}_{3}$ or aromatic functional groups (Aske et al., 2001). A 
comparison of average spectra between petroleum contaminated soils and non-contaminated soils is shown in Figure 1 (Chakraborty et al., 2015). These are similar in terms of optical intensity only in the visible range (Clark et al., 1990). However, in the NIR range the reflectance decreases with increasing contamination leading to increased absorbance and thus less reflectance than the non-contaminated samples (Hoerig et al., 2001).

A considerable amount of literature has been published on the application of vis-NIR spectroscopy for the rapid estimation of soil PHCs (Okparanma and Mouazen, 2013; Chakraborty et al., 2010; Bray et al., 2009; Malley et al. 1999; Okparanma et al., 2014a). For example, Okparanma et al. (2014a) assessed the ability of vis-NIR diffuse reflectance spectroscopy (vis-NIR DRS) (350-2500 nm) for the measurement of petroleum hydrocarbon contamination in soils. The authors used sequential ultrasonic solvent extraction-gas chromatography (SUSE-GC) to measure PAH in soil samples. Both, the SUSE-GC measured data and the vis-NIR soil spectral data were pulled into one data matrix, and further subjected to a partial least square regression analysis. Prediction models with $\mathrm{R}^{2}$ values ranging between 0.77 and 0.89 , residual prediction deviation (RPD) values ranging between 1.86 and 3.12 , and root mean square error ranging between 1.16 and $1.95 \mathrm{mg} / \mathrm{kg}$ were obtained. Okparanma et al. (2014a) recommended that the method may be promising for quick evaluation of the spatial variability of PAHs in petroleum-contaminated soils and could assist site risk assessment.

The opportunity of employing vis-NIR DRS for the mapping of PAHs and the total toxicity equivalent concentration (TTEC) of PAH mixtures in different petroleum-discharge sites in Niger Delta, Nigeria, was investigated by Okparanma et al. (2014b). The t-test results showed no significant $(\mathrm{p}>0.05)$ discrepancies between the GC-MS measured and vis-NIRS predicted PAH and TTECs maps (kappa coefficients $=0.19-0.56$ ). The authors concluded that vis-NIR 
technique had good potential for monitoring hydrocarbon contamination in petroleumdischarged area. Okparanma and Mouazen (2013) assessed the applicability of vis-NIR DRS (350-2500 nm) to evaluate phenanthrene in 150 diesel-seeded soils. They used PLSR with cross-validation and obtained RPD values of 2.0 and 2.32, root mean square error of prediction (RMSEP) values of 0.21 and $0.25 \mathrm{mg} / \mathrm{kg}$, and $\mathrm{R}^{2}$ values of 0.75 and 0.83 for validation and calibration, respectively. Other studies have investigated the capability of visNIR spectroscopy to assess PAHs in artificially contaminated soils (Bray et al., 2009; Malley et al., 1999; Okparanma and Mouazen, 2012). Using PLSR, Okparanma and Mouazen (2012) achieved an RMSEP of $0.2010 \mathrm{mg} / \mathrm{kg}$, RPD of 2.75 and an $\mathrm{R}^{2}$ of 0.89 for the calibration model. They suggested the potential of the technique to quantitatively characterise PAH in diesel-contaminated soils. With an ordinal logistic regression method, Bray et al. (2009) predicted total PAHs and benzo[a]pyrene using the vis-NIR technique. Their results showed good accuracy (90\%) and a moderate to high false-positive rate at the low and high total PAH threshold, respectively.

NIR reflectance spectroscopy (1100-2498 nm) in combination with a step-by-step multiple linear regression were employed to predict the concentration of TPH in field dieselcontaminated soils (Malley et al., 1999), reporting a low accuracy and high prediction error. The low performance was attributed to (but not limited to) the small number of samples used and the inconsistency in the reference laboratory results. Chakraborty et al. (2010) evaluated the performance of vis-NIR DRS $(350-2500 \mathrm{~nm})$ to quantify PHCs contamination in soils. To achieve their research objective, 46 contaminated and control samples were collected from Louisiana, USA, after which the soil was scanned with a vis-NIR DRS as either 'field-moist intact' or 'air-dry' samples. Using both PLS regression and boosted regression tree (BRT) calibration models, the authors obtained a $\mathrm{R}^{2}$ of 0.64 and a RPD of 1.70 as the best result for the prediction of TPH content from the field-moist scans, since the air-dried scans yielded 
0.57 and 1.25 for $\mathrm{R}^{2}$ and RPD, respectively. Authors concluded that there is the possibility of using vis-NIR DRS as a proximal soil-sensing tool for PHCs. However, this is true only for the analysis with moist soil samples, where the prediction performance was acceptable.

The applicability of vis-NIR for the analysis of TPH content in control soil samples seeded (spiked) with diesel and crude oil, and control soil mixed with oil was examined by Forrester et al. (2010), who reported a RMSE range of $4500-8000 \mathrm{mg} / \mathrm{kg}$ out of the TPH range of 0$100000 \mathrm{mg} / \mathrm{kg}$. Although the authors made no conclusions on their result, we concluded that since the RMSE upper limit is $8 \%$ of the upper TPH range, the result achieved is of small error. Thus, NIRS is a suitable screening tool for TPH measurement in soil. To examine the detection ability of vis-NIR for TPH in soils, Schwartz et al. (2012) utilised contaminated soils with a definite concentration of petroleum. Hydrocarbon analysis was carried out in three different certified laboratories; hence, the exact procedure was kept confidential. However, all the laboratories used the general methodology for the adjusted EPA 418.1 method. The measured results from these different certified laboratories in Israel were compared, and authors observed discrepancies between them; Laboratory A: 4575, 5288, 4932; Laboratory B: 6179, 6292, 6236; and Laboratory C: 3730, 4480, 4111 (represents minimum, maximum, and average concentrations of TPH (ppm), respectively. However, a satisfactory correlation from the plot of reflectance spectroscopy (4617 ppm) and the laboratories TPH (4500 ppm) versus projected TPH (5674 ppm) results was established. Consequently, they inferred that the accuracy of the vis-NIR spectroscopy technique was as promising as the commercial laboratories, and therefore it could be a feasible on-line sensing tool.

In a recent study, Chakraborty et al. (2015) combined XRF technique with vis-NIR diffuse reflectance spectroscopy (DRS) to produce an optimised model to predict PHC in soils from Texas, USA. Using a combined penalised spline regression (PSR) and random forest 
regression (RFR) modelling approach, authors obtained a $\mathrm{R}^{2}$ of 0.78 and RPD of 2.19 and concluded that the this synthesised modelling methodology produced a better result compared to individual model based analysis, which resulted in RPD of 1.64, 1.86, and 1.96 for RFR, PSR and PLSR analyses, respectively.

Despite the potential advantage of this technique for measuring soil properties and detecting PHC in soils, only few studies have been carried out on contaminated sediment and soil samples. Therefore, further research is needed to boost the application and opportunities for spectroscopy in the future. Especially, vis-NIR DRS holds promising potential for rapid and cost-effective measurement of PHCs in soils, to inform risk assessment and decision support for remediation of agricultural lands. It is also important to mention that this technology offers portable systems that can be taken to the field to enable in situ measurement of PHCs, which is a fundamental requirement for accurate site-specific land reclamation, based on high sampling resolution data (Okparanma et al., 2014b). However, it should be noted that, visNIRS results can be affected by soil factors such as moisture content, soil types, ambient lights, etc.). Therefore, accounting for these external factors affecting the prediction performance is a key step for successful implementation of this sensing technology as a portable tool for field screening of PHCs in soils. Furthermore, it is important to note that accuracy reported so far by different research groups indicates that these detection methods are at a semi-quantitative stage, where more works to improve performance is needed.

\section{(Figure 1)}

\subsubsection{Mid-infrared (MIR) spectroscopy}

The principle of mid-infrared DRS is that molecules possess definite frequencies, and they vibrate in accordance with different energy levels (Horta et al., 2015). The fundamental vibrations of molecules when subjected to energy (e.g., light source) take place in the MIR 
range, which lead to absorption of light, to various degrees, with a specific energy quantum corresponding to the difference between two energy levels. As the energy quantum is directly related to frequency, the resulting absorption spectrum produces a characteristic shape that can be used for analytical purposes (Stenberg et al., 2010). Spectroscopy in the MIR range (2500-25000 nm) can rapidly capture soil information (Horta et al., 2015) important for soil contaminants assessment.

MIR spectroscopy (MIRS) is one of the rapid and cost-effective techniques developed for soil analyses (Bellon-Maurel and McBrtney, 2011). MIRS has been demonstrated to be a better measurement tool for soil total carbon, organic carbon, and inorganic carbon than vis-NIR spectroscopy(McCarty et al., 2002, McCarty and Reeves, 2006). MIR spectroscopy yields more informative spectra and peaks compared to NIR, which is characterised by broad bands of overtones and combinations (Reeves, 2010; Soriano-Disla et al., 2014). However, the superior performance of MIRS to vis-NIR is yet to be established in all soil science research (Vohland et al., 2014), although some literature indicated MIR spectroscopy to overcome the vis-NIR spectroscopy.

The potential application of MIR for the detection of PHCs in soils has been reported to be an excellent tool for hydrocarbon concentration in soils (Wartini et al., 2017; Horta et al., 2015). However, MIR accuracy and reproducibility are influenced by sample inhomogeneity and thus requires extra sample preparation (Horta et al., 2015). The applicability of MIR for the quantification of TPH in a control sample spiked with diesel and crude oil, and a control soil mixed with oil was examined by Forrester et al. (2010); they reported a smaller RMSE range of $2000-4000 \mathrm{mg} / \mathrm{kg}$ compared to NIRS $(2000-8000 \mathrm{mg} / \mathrm{kg}$ ), out of the TPH range of $0-100$ $000 \mathrm{mg} / \mathrm{kg}$. Furthermore, Forrester et al. (2013) used real contaminated soil samples (205) to demonstrate the ability of MIR spectroscopy to detect TPH in soils, reporting RMSE $<1000$ $\mathrm{mg} / \mathrm{kg}$ for the $0-15000 \mathrm{mg} / \mathrm{kg}$ of TPH content range, and recommended that this accuracy 
might be satisfactory in terms of screening. This review also presents an overview of analytical techniques, analyte, multivariate analyses and accuracy of different methods available for the analysis of soil contaminants (Table 2).

\section{(Table 2)}

Like in the vis-NIR spectroscopy case, advances in MIR spectroscopy have made portable systems available for in situ measurement of different soil properties, including PHCs. However, it should be noted here that, although sharp and clear signatures of organic pollutants can be obtained with MIR spectroscopy, which is encouraging for accurate measurements. MIR spectroscopy is susceptible to soil moisture content (MC), limiting field applications. In comparison with NIR spectroscopy, the effect of water on spectral response is more severe with MIR spectroscopy. This necessitates advanced data mining techniques to remove the influence of MC. Recent studies on the use of the vis-NIR spectroscopy for the measurement of other soil properties proved that $\mathrm{MC}$ effect can be removed by adopting direct standardisation of external parameter orthogonalization techniques (Ji et al., 2015). These techniques are yet to be tested in the MIR spectroscopy, particularly for PHC contamination detection. Furthermore, other approaches that can be adopted to remove the water effect in soil samples is to classify spectra into different soil water classes, for each specific calibration models of soil consistent is developed (Mouazen et al., 2006). From the brief review on MIR spectroscopy, we can conclude that this technique is promising for the measurement of various soil PHCs contaminants. However, MIR accuracy and reproducibility are affected by sample heterogeneity, thus requiring extra sample processing. The technique is field-deployable (Sorak et al., 2012) though MC effect is a limiting factor in the field. Nevertheless, advanced data mining approaches can remove the influence on MC. 


\section{Multi-sensor and data fusion approach}

A multi-sensor and data fusion approach has recently been introduced in digital agriculture, as a tool to improve soil and crop management (Kuang et al., 2012; Grunwald et al., 2015). Also, recent reports confirmed that this approach was extended to the environmental sector e.g., to measure and manage PHC in soils (e.g., Horta et al., 2015; Chakraborty et al., 2015). However, it is worth to stress that multi-sensor and data fusion approach is more common for field measurement scenarios, which allow overcoming the major shortcoming of these technologies regarding accuracy. In this sense, it can be hypothesised that by the integration of more than one field sensor and advanced data fusion modelling, improvement in calibration accuracy is expected compared to that provided by individual sensing technology. Although field measurement methods have been used independently for environmental analysis, they are yet to be integrated into single use (data fusion) for swift and better environmental analysis. While multi-sensor is the use of more than one sensor (hardware) when collecting multi-data layer from one sample or spot, data fusion is the integration and modelling of the multi-data layer from different sources to produce more accurate (reliable) quantitative assessment of a property, which could not be attained from a single source (Horta et al., 2015).

Data fusion, as a methodology for environmental analysis, is new and has so far attracted little attention in the literature. Fused XRF data and vis-NIR spectra was used to produce an optimised model for swift and more accurate measurement of soil PHC in Texas (Chakraborty et al., 2015). Using spectral libraries and field validation, Horta et al. (2015) reported that the synergistic use of vis-NIR and XRF spectrometry data is possible for better soil contaminant analysis, nevertheless, they recommended also the need to develop unique calibration methods. However, portable sensing technologies are not restricted to vis-NIRS, but MIRS (Sorak et al., 2012), micro spectroscopy, XRFS, GC-MS and others that may well 
be integrated and their multi-layer data analysed. Currently, there is no study yet integrating XRFS, MIRS, and vis-NIRS optical sensors for the evaluation of soil PHCs. Thus, a fieldportable integrated framework of $\mathrm{XRF}+\mathrm{MIR}$, vis-NIR+MIR or $\mathrm{XFR+vis-NIRS+MIR}$ to analyse PHCs in soils and sediments has never been proposed. The synergistic use of these combinations, albeit complexity and increased capital cost, is portability, requirement for little or no consumable, and minimum or no samples preparation. With these advantages, the higher capital cost would be recovered within a short period of time, as cost of analysing TPH per sample can be high. Either of the hybrids would benefit environment regulators and remediation experts. The workflow for the "newly integrated approach of multi-sensor and data fusion" based on chemometrics, or machine learning is illustrated in Figure 2. In this approach the three spectrometers are transferred to the field (in situ measurement), or soil samples are brought to the laboratory (laboratory-based analysis). The multi-data layers obtained from the three sensing technologies are pooled together in one matrix, subjected to data pre-processing, before multivariate statistics (e.g., PLSR) and machine learning (e.g. artificial neural network ANN), support vector machine (SVM), and random forest (RF) modelling techniques are used to establish calibration models to predict PHCs in soils. From the few successes made in earlier studies (Chakraborty et al., 2015; Wang et al., 2015) (Table 3) with data fusion technology, it is expected that the multi-sensor and data fusion outlined in the present paper would be effective and feasible for analysing soil PHCs contaminants. This has to be validated with experimental work in the future.

\section{(Figure 2)}

(Table 3)

\section{Decision making in selecting a detection techniques: advantages and limitations}


The first step towards decision making on the best technique to measure a source of contamination is driven by time, cost, and the final application of results. For example, in cases where time is not a crucial factor and accuracy is more appealing, laboratory measurement techniques are the most appropriate option, as accuracy is higher than field techniques. However, with recent advances in sensing technologies and IT infrastructure, field equipment become available, which may soon become real competitors of current tradition laboratory analytical techniques (e.g., the gas chromatography); particularly, if the current challenges, e.g. accuracy, can be overcome or at least minimised with advanced modelling techniques. One example of potential solution is the multi-sensor and data fusion approach detailed in section 3. A wide range of field measuring techniques is available for quick measurement of PHCs in soil (Okparanma and Mouazen, 2013), although no single technique measures the whole range of PHCs. Thus, the detection of these contaminants depends on the samples and the analytical technique employed (Deeks et al., 2014). Therefore, choice of technique is important in conducting effective measurement of PHCs in soil and sediment. Field measuring techniques should be cost-effective, timesaving, portable and provide sufficient accuracy in detecting and monitoring PHCs contamination levels in soil and sediment, rather than expensively analysing samples later in the laboratory (Barnes, 2009). These advantages allow field techniques to enable collecting a high number of samples per field area in a relatively short period, which is a crucial requirement for precision land reclamation (Okparanma et al., 2014b). This is because by enabling high sampling resolution to be collected, better spatial sample coverage and thus a better understanding and characterisation of the contaminated area can be obtained. The accuracy and limits of detection in field measuring methods are advancing and some may be applied to detect low concentration or even targeted chemicals (Deeks et al., 2014). However, the analytical quality 
of these techniques may be less accurate, and at a semi-quantitative range, compared to laboratory analysis for the measurement of PHCs in soils and sediments.

Table 4 shows the factors influencing the decision making process in selecting analytical techniques. Factors such as analysis run time, analysis cost per sample, operational skills and limitations were considered for decision-making. Among the techniques, there are currently no analysis cost per sample for vis-NIR, PXRF and portable GC-MS methods. Thus, there is an active research need in this area to enhance the decision-making process for analytical methods in environmental analysis. There is also need for research into the analysis run time of vis-NIR spectroscopy. In the area of operational skills, field GC, portable GC-MS, vis-NIR spectroscopy and PXRF require medium to high skill. While headspace FIDs and headspace PIDs require low to medium skill, Immunoassay test kits requires medium skill. To select the best analytical technique for environmental analysis, the highlighted research needs have to be addressed.

\section{(Table 4)}

\section{Conclusions}

A plethora of chromatographic and spectroscopy techniques and extraction methods for the analysis of petroleum hydrocarbons (PHCs) in soil and sediments are available in the literature. This literature review has discussed both laboratory and field techniques, and showed that no method is problem-free, but there are issues of different magnitudes. For example, it has been documented that both near infrared spectroscopy (NIRS) and mid infrared spectroscopy (MIRS) are affected by moisture content (MC), which has to be accounted for in field measurement protocols by adopting appropriate modelling techniques. The high selective and sensitive of gas chromatographic lab-based techniques makes them the preferred choice for the identification and quantification of hydrocarbon contamination in 
environmental samples. However, they can be time-consuming and required a high level of expertise. In contrast, field portable GC techniques offer direct on-site analysis of samples for quick detection and measurement.

Recent advances made with field spectroscopy methods (e.g., X-ray fluorescence (XRF), mid-infrared (MIR) and visible and near infrared (vis-NIR)) suggest that the development of field techniques towards practical applicability still have to follow; and the literature provides rather proof-of-concepts-studies so far. However, these field-portable methods and the implementation of a multi-sensor and data fusion approach improve PHCs prediction accuracy over individual sensing technologies. We believe that there are huge research opportunity for improved field measurements of contaminants in soil and sediment if data fusion from different optical sensors could be integrated. The best spectroscopy combination candidates from environmental prospective, and which have not been investigated yet, include $\mathrm{XRF}+\mathrm{MIR}$, vis-NIR+MIR or XFR+vis-NIRS+MIR. There is the chance that this synergy-rather than a single technique-could produce more reliable and accurate information for the mapping of contaminants in petroleum release sites. MIR and vis-NIR spectroscopy are candidate techniques for analysing PHCs, while XRF is widely known for the analysis of heavy metals and inorganic compounds. However, the fusion of XRF elemental data and vis-NIR spectra has shown to improve the quantification accuracy of soil TPH.

When optimal sensor combination, data mining and modelling technique is established, and when a successful technique to remove the negative influences on moisture content is implemented, high sampling resolution per unit field area can be collected in situ; this will assist in contaminated site remediation, contaminated land management, and risk assessment of petroleum hydrocarbon on human and welfare health. 
In order to test the feasibility and potential application of the combination of Vis-NIR, MIR and XRF spectrometry spectral data for rapid and cost-effective analysis of soil PHCs contaminants a pilot study needs to be conducted. In addition, multivariate modelling needs to be carried out with the conjoint data, using nonlinear analytical methods including artificial neural network and support vector machine, instead of commonly applied linear methods like PLS regression. Further work is also imperative in the area of analysis run time for generic field measurement methods like Vis-NIRS. This would facilitate selection of techniques for petroleum hydrocarbons detection in soil.

Acknowledgements: The authors gratefully acknowledge the Petroleum Technology Development Fund (PTDF) of Nigeria, whose financial assistance in the form of doctoral studentship has led to this publication.

\section{References}

American Society for Testing and Materials (1992). Standard testing methods for Boiling Range Distribution of Petroleum Fraction by Gas Chromatography D2887-89, ASTM Annual Book of Standards, Vol. 05.02, ASTM, Philadelphia, 483.

Aske, N., Kallevik, H., and Sjöblom, J. (2001). Determination of saturate, aromatic, resin, and asphaltenic (SARA) components in crude oils by means of infrared and nearinfrared spectroscopy. Energy \& Fuels 15, 1304-1312.

Avila, B.M.F., Aguirar, A., Gomes, A.O., and Azevedo, D.A. (2010). Characterization of Extra Heavy Gas Oil Biomarkers usingComprehensive Two-dimensional Gas Chromatography Coupled to Time-of-Flight Mass Spectrometry, Org.Geochem., 41, 863.

Barman, B.N., Cebolla, V.L., and Membrado, L. (2000). Chromatographic techniques for petroleum and related products. Critical Reviews in Analytical Chemistry, 30:75-120 
Barnes, B. (2009). Framework for the use of rapid measurement techniques (RMT) in the risk management of land contamination. Environ. Agency Bristol, UK.

Becker, R., Koch, M., Wachholz, S., and Win, T. (2002). Quantification of total petrol hydrocarbons (TPH) in soil by IR-spectrometry and gas chromatography - conclusions from three proficiency testing rounds. Accreditation and Quality Assurance, 7, 286-289.

Boczkaj, G., Przyjazny, A and Kaminski, M. (2011). A new procedure for the determination of distillation temperature distribution of high-boiling petroleum products and fractions. Anal. Bioanal Chem, 399, 3253-3260.

Brassington, K.J, Pollard, S.T.J., and Coulon, F. (2010). Weathered hydrocarbon wastes: a risk assessment primer," in Handbook of hydrocarbon and Lipid Microbioloy, in: Timmis, K.N., McGenity, T., Van Der Meer, J.R., De Lorenzo, V. (Eds.), Handbook of Hydrocarbon and Lipid Microbiology. Springer Berlin, pp. 2488-2499.

Bray, J.G.P., Rossel, R.V., and McBratney, A.B. (2009). Diagnostic screening of urban soil contaminants using diffuse reflectance spectroscopy. Soil Res., 47, 433-442.

Bray, J.G.P., Rossel, R.V., and McBratney, A.B. (2010). Diagnostic screening of urban soil contaminants using diffuse reflectance spectroscopy. In Proximal Soil Sensing, Viscarra Rossel, R.A., McBratney, A.B., and Minasny, B., Eds. Springer-Verlag:Berlin, Germany, 191-199.

Cavanagh, J.E., Juhasz, A.L., Nichols, P.D., Franzmann, P.D., and McMeekin, T.A. (1995). Analysis of microbial hydrocarbon degradation using TLC-FID. Journal of Microbiological Methods 22, 119-130.

California Geotechnical Services, 2016. Portable GC Frog 4000 for Environmental Remediation, Air Quality Testing, and More. (Available at: http://www.geotechnical.net/portable-gc-frog-4000.shtml, accessed 10.04.2016)

Chakraborty, S., Weindorf, D.C., Li, B., Aldabaa, A.A.A., Ghosh, R.K., Paul, S., and Ali, M.N. (2015). Development of a hybrid proximal sensing method for rapid identification of petroleum contaminated soils. Sci. Total Environ., 514, 399-408.

Chakraborty, S., Weindorf, D.C., Morgan, C.L.S., Ge, Y., Galbraith, J.M., Li, B., and Kahlon, C.S. (2010). Rapid identification of oil-contaminated soils using visible nearinfrared diffuse reflectance spectroscopy. J. Environ. Qual., 39, 1378-1387.

Chibwe, L., Davie-Martin, C.L., Aitken, M.D., Hoh E., Massey Simonich, S.L. (2017). 
Identification of polar transformation products and high molecular weight polycyclic aromtaic hydrocarbons (PAHs) in contaminated soil floolowing remediation. Sci. Total Environ., 599-600, 1099-1107

Chimezie, A., Anthony, O., Pete, P., Herbert, C., Ukpo, G., Ogah, C. (2005). GC/MS analysis of polynuclear aromatic hydrocarbons in sediment samples from the Niger Delta region.Chemosphere 60, 990-997.

Clark,R.N., King, T.V.V., Klejwa, M., Swayze, G.A., and Vergo, N. (1990). High spectral resolution reflectance spectroscopy of minerals.J. Geophys. Res., 95 (B8), 12653-12680.

Cortes, J.E., Suspes, A., Roa, S., Gonzalex, C and Castro, H.E. (2012). Total Petroleum Hydrocarbons by Gas Chromatography inColombian Waters and Soils. American Journal of Environmental Science, 8(4), 396-402.

Cloutis, E.A. (1989). Spectral reflectance properties of hydrocarbons: remote-sensing implications. Science, 245, 165-168.

Coulon, F., Whelan, M.J., Paton, G.I., Semple, K.T., Villa, R., and Pollard, S.J.T. (2010). Multimedia fate of petroleum hydrocarbons in the soil: oil matrix of constructed biopiles. Chemosphere, 81, 1454-62.

Coulon F., Brassington K.J., Bazin R., Linnet P.E., Thomas K.A., Mitchell T.R., Lethbridge G., Smith J.W.N., and Pollard S.J.T. 2012. Effect of fertiliser formulation and bioaugmentation on biodegradation and leaching of crude oils and refined products in soils. Environmental Technology $233,1879-1893$.

Coulon F. and Wu G. 2017. Determination of petroleum hydrocarbon compounds from soils and sediments using ultrasonic extraction. In: Hydrocarbon and Lipid Microbiology Protocols McGenity T.J et al. (eds.) Springer-Verlag Berlin Heidelberg, pp 31-46.

Cozzolino, D. (2015). Near infrared spectroscopy as a tool to monitor contaminants in soil, sediments and water - state of the art, advantages and pitfalls. Trends Environ. Anal. Chem. 9, 1-7.

Current, R. W., and Tilotta, D. C. (1997). Determination of total petroleum hydrocarbons in soil by on-line supercritical fluid extraction-infrared spectroscopy using a fibre-optic transmission cell and a simple filter spectrometer. Journal of Chromatography A, 785, 269-277. 
Deeks, L., Coulon, F., Tibeth, M., Kirk, G., Mouazen, A.M., Tothill, L., and Walton, C. (2014). Practical guidance document for field screening technologies of hydrocarbons and associated metals in soil and water. Energy Institute Technology Publication, ISBN 9780852937044. Available at:http://publishing.energyinst.org/publication/eitechnical-publications/environment/refinery-emissions/practical-guidance-ontechnologies-for-field-screening-hydrocarbons-and-associated-metals-in-soil-andwater.

Dettmer-Wilde, K. and Engewald W. (ed) (2014) Practical gas chromatography - A comprehensive reference, Springer Heidelberg, ISBN 978-3-642-54639-6, 893 pp

Dunn, K., Chilingarian, G.V., Lian, H., Wang, Y.Y and Yen, T.F. (2000). Chapter 11: Analysis of Asphalt and its components by Thin-Layer Chromatography. Development in Petroleum Science, 40, pp. 305-317.European Standard ENISO 22155 (2016). Soil quality-gas chromatographic determination of volatile aromatic and halogenated hydrocarbons and selected ethers-static headspace method.

EPA (1997). Chapter VI Field methods for the analysis of petroleum hydrocarbons.In: EPA Expedited Site Assessment Tools for Underground Storage Tank Sites: A 87 Final draft guide for regulators. United States Environmental Protection Agency Office of Underground Storage Tanks, OSWER, Washington DC, pp. VI-1 to VI-52.

EPA Method 418.1. (1978). Total Recoverable Petroleum Hydrocarbons by IR. Government Printing Office, Washington, DC, USA.

Fan, C. Y., Krishnamurthy, S., and Chen, C. T. (1994). A critical review of analytical approaches for petroleum contaminated soil. In: T. A. O'Shay and K. B. Hoddinott (Editors). Analysis of soil contaminated with petroleum constituents. American Society for Testing and Materials ASTM STP 1221, Philadelphia, PA. pp. 61-74

Forrester, S., Janik, L., McLaughlin, M., and Gilkes, R.J. (2010). An infrared spectroscopic test for total petroleum hydrocarbon (TPH) contamination in soils., in: Proceedings of the 19th World Congress of Soil Science: Soil Solutions for a Changing World, Brisbane, Australia, 1-6 August 2010. Working Group 1.5 Soil Sense: Rapid Soil Measurements. pp. 13-16.

Forrester, S.T., Janik, L.J., McLaughlin, M.J., Soriano-Disla, J.M., Stewart, R., and Dearman, B. (2013). Total Petroleum Hydrocarbon Concentration Prediction in Soils Using Diffuse Reflectance Infrared Spectroscopy. Soil Sci. Soc. Am. J., 77(2), 450-460. 
Gałuszka, A., Migaszewski, Z.M., Namieśnik, J. (2015). Moving your laboratories to the field - Advantages and limitations of the use of field portable instruments in environmental sample analysis. Environ. Res., 140, 593-603.

Grob, R.L and Garry, E.F. (2004). Modern practice of gas chromatography $4^{\text {th }}$ edition.Wiley and Sons, NewYork.

Grunwald, S., Vasques, G.M., \& Rivero, R.G. (2015). Fusion of Soil and Remote Sensing Data to Model Soil Properties. Adva., Agro., 131, 1-191.

Giri, A., Coutriade, M., Racaud, A., Okuda, K., Dane, J., Cody, R.B., Focant, J-F. (2017) Molecular characterisation of volatiles and petrochemical base oils by photo-ionization GC $\times$ GC-TOF-MS. Anal. Chem., 89, 5395-540.

Harris, C.M. (2003). Today’s chemist at work. American Chemical Society, 33-38.

He, Y., Tang, L., Wu, X., Hou, X., and Lee, Y, I. (2007). Spectroscopy: the best way toward green analytical chemistry? Appl. Spectrosc. Res., 42, 119-138.

Hibbert, D.B. (2012). Experimental design in chromatography: A tutorial review. J. Chromatogr. B, 919, 2-13.

Hoerig, B., Kuehn, F., Oschuetz, F., and Lehmann, F. (2001). HyMap hyperspectral remote sensing to detect hydrocarbon. Int. J. Remote Sens., 8, 1413-1422.

Horta, A., Malone, B., Stockmann, U., Minasny, B., Bishop, T.F.A., McBratney, A.B., Pallasser, R., and Pozza, L. (2015). Potential of integrated field spectroscopy and spatial analysis for enhanced assessment of soil contamination: A prospective review. Geoderma, 241-242, 180-209.

Hou, X., He, Y., and Jones, B.T. (2004). Recent Advances in Portable X-Ray Fluorescence Spectrometry. Appl. Spectrosc. Rev., 39, 1-25.

Ji, W., Li, S., Chen, S., Shi, Z., Viscarra Rossel, R.A. and Mouazen, A.M. (2015). Prediction of soil attributes using the Chinese soil spectral library and standard spectra recorded at field conditions. Soil Tillage Res., 155, 492-500.

Koshy, V.J and Sudhakar, P. (2013). Gas Chromatographs for Environmental Field Analysis. Available in www.envirotech-online.com. Accessed 18 April 2017.

Kuang, B., Mahmood, H.S., Quraishi, Z., Hoogmoed, W.B., Mouazen, A.M., and van Henten, E.J. (2012). Sensing soil properties in the laboratory, in situ, and on-line: a 
review. In Donald Sparks, edittors: Advances in Agronomy, 114, AGRON, UK: Academic Press, 155-224.

Li, S., Cao, J., and Hu, S. (2015). Analyzing hydrocarbon fractions in crude oils by twodimensional gas chromatography/time-of-flight mass spectrometry under reversed-phase column system. Fuel, 158, 191-199.

Lorenzi, D., Cave, M., and Dean, J.R. (2010). An investigation into the occurrence and distribution of polycyclic aromatic hydrocarbons in two siil size fractions at a former industrial site in NE England, UK using in situ PFE-GC-MS. Environmental Geochemistry and Health, 32,553-565.

Malley, D.F., Hunter, K.N., Webster, G.R.B., Malley, D.F., Hunter, K.N., Webster, G.R.B., and Barrie, G.R. (1999). Analysis of Diesel Fuel Contamination in Soils by NearInfrared Reflectance Spectrometry and Solid Phase Microextraction-Gas Chromatography. Soil Sediment Contam., 8, 481-489.

Marriot, P.J., Chin, S,T., Maikhunthod, B., Schmarr, H.G., and Bieri, S. (2012). Multidimensional gas chromatography. Trends in Analytical Chemistry, 34, 1-21.

McCarty, G.W., and Reeves, J.B. (2006). Comparison of near infrared and mid infrared diffuse reflectance spectroscopy for field-scale measurement of soil fertility parameters. Soil Sci., 171, 94-102.

McCarty, G.W., Reeves, J.B., Reeves, V.B., Follett, R.F., and Kimble, J.M. (2002). Midinfrared and near-infrared diffuse reflectance spectroscopy for soil carbon measurement. Soil Sci. Soc. Am. J., 66, 640-646.

McMahon, G. (2007). Portable instruments in the laboratory, Analytical In- strumentation: A Guide to Laboratory, Portable and Miniaturized Instruments. John Wiley \& Sons, Ltd., Chichester, UK

Mouazen, A.M., Steffens, M., and Borisover, M. (2016). Reflectance and fluorescence spectroscopy in soil science-Current and future research and developments. Soil Tillage Res., 155, 448-449.

Mouazen, A.M., De Baerdemaeker, J., and Ramon, H. (2006). Towards development of online soil moisture content sensor using a fibre-type NIR spectrophotometer. Soil Tillage Res., 80, 171-183.

Napolitano, G.E., Richmong, J.E., and Stewart, A.J. (1998). Characterisation of petroleum- 
contaminated soils by Thin-Layer Chromatography with Flame Ionisation Detection. $J$ of Soil Contamination, 7:6. 709-724.

O’Rourke, S.M., Minasny, B., Holden, N.M., McBratney, A.B. (2016). Synergistic Use of Vis-NIR, MIR, and XRF Spectroscopy for the Determination of Soil Geochemistry. Soil Sci. Soc. Am. J., 80:888-899

Okparanma, R.N., Coulon, F., Mayr, T., and Mouazen, A.M. (2014b). Mapping polycyclic aromatic hydrocarbon and total toxicity equivalent soil concentrations by visible and near-infrared spectroscopy. Environ. Pollut., 192, 162-170.

Okparanma, R.N., Coulon, F., and Mouazen, A.M. (2014a). Analysis of petroleumcontaminated soils by diffuse reflectance spectroscopy and sequential ultrasonic solvent extraction-gas chromatography. Env. Pollut., 184, 298-305.

Okparanma, R.N., and Mouazen, A.M. (2013). Combined Effects of Oil Concentration, Clay and Moisture Contents on Diffuse Reflectance Spectra of Diesel-Contaminated Soils. Water, Air, Soil Pollut., 224, 1539.

Okparanma, R.N., and Mouazen, A.M. (2012). Risk-based characterisation of hydrocarbon contamination in soils with Visible and near-infrared diffuse reflectance spectroscopy., in: Soil and Water Engineering. International Conference of Agricultural EngineeringCIGR-AgEng 2012: Agriculture and Engineering for a Healthier Life, Valencia, Spain, 8-12 July 2012. pp. C-0657.

Osborne, B.G., Fearn, T., and Hindle, P.H. (1993). Practical NIR spectroscopy with applications in food and beverage analysis. Longman scientific and technical. AddisonWesley Longman Ltd: Harlow UK.

Pan, D., Wang, J., Chen C., Huang, C., Cai, Q., Yao, S. (2013) Ultrasonic assisted extraction combined with titatnium plate based solid phase extraction for the anlysis of PAHs in soil samples by HPLC-FLD. Talenta, 108:117-122

Pasquini, C. (2003). Near infrared spectroscopy: Fundamentals, practical aspects and analytical applications. J. Braz. Chem. Soc., 14, 198-219.

Pollard, S.J.T., Hrudey, S.E., Rawluk, M., and Fuhr, B.J. (2004). Characterisation of weathered hydrocarbon wastes at contaminated sites by GC-simulated distillation and nitrous oxide chemical ionisation GC/MS, with implications for bioremediation. Journal of Environmental Monitoring, 6, 713-718. 
Poster, D.L., Schantz, M.M., Sander, L.C., and Wise, S.A. (2006). Analysis of polycyclic aromatic hydrocarbons (PAHs) in environmental samples: a critical review of gas chromatographic (GC) methods. Anal. Bioanal. Chem. 386, 859-881.

Risdon, G., Pollard, S.J.T., Brassington, K.J., McEwan, J.N., Paton, G., Semple, K., and Coulon, F. 2008. Development of an analytical procedure for weathered hydrocarbon contaminated soils within a UK risk-based framework. Anal. Chem., 80, 7090-7096.

Reeves, J.B. (2010). Near- versus mid-infrared diffuse reflectance spectroscopy for soil analysis emphasizing carbon and laboratory versus on-site analysis: Where are we and what needs to be done? Geoderma 158, 3-14.

Sarowha, S.L.S., Sharma, B.K., Sharma, C.D and Bhagat, S.D. (1997). Characterisation of petroleum Heavy Distillates using HPLC and Spectroscopic Methods, Energy Fuel., 11,566 .

Schwartz, G., Ben-Dor, E., and Eshel, G. (2012). Quantitative analysis of total petroleum hydrocarbons in soils: comparison between reflectance spectroscopy and solvent extraction by 3 certified laboratories. Appl. Environ. Soil Sci., 2012, 1-11.

Song Y.F., Jing X., Fleischmann S., Wilke B-M. 2002. Comparative study of extraction methods for the determination of PAHs from contaminated soils and sediments. Chemosphere. 48, 993-1001.

Sorak, D., Herberholz, L., Iwascek, S., Altinpinar, S., Pfeifer, F., and Siesler, H.W. (2012). New development $\mathrm{s}$ and applications of handheld Raman, mid-infrared, and nearinfrared spectrometers. Appl. Spectrosc. Rev., 47 (2), 83-115.

Stenberg, B., Rossel, R. A. V., Mouazen, A. M., and Wetterlind, J. (2010). Visible and Near Infrared Spectroscopy in Soil Science. Adv. Agron., 107, 163-215.

Tissot, B.P., and Welte, D.H. (1984). Petroleum formation and occurrence . Berlin Heidelberg: Springer-Verla

Tran, T.C., Logan, G.A., Grosjean, E., Ryan, D., and Marriott, P.J. (2010). Use of comprehensive two-dimensional gas chromatography time-of-flight mass spectrometry for the characterisation of biodegradation and unresolved complex mixtures in petroleum. Geochim Cosmochim Acta, 74:6468-84.

Ulmanu, M., Anger, I., Gament, E., Mihalache, M., Plopeanu, G., Ilie, L., others (2011). 
Rapid determination of some heavy metals in soil using an X-ray fluorescence portable instrument. Res. J. Agric. Sci., 43, 235-241.

Vallejo, B., Izquierdo, A., Blasco, R., del Campo, P.P., and de Castro, M.D.L. (2001). Bioremediation of an area contaminated by a fuel spill. J. Environ. Monit. 3, 274-280.

Van Liedekerke, M., Prokop, G., Rbl-Berger, S., Kibblewhite, M., and Lowagie, G. (2014). Progress in the management of contaminated sites in Europe, Reference Report by the Joint Research Centre of the Eurpean Commission 72.

Viscarra Rossel, R. A., McGlynn, R.N., and McBratney, A. B. (2006). Determining the composition of mineral-organic mixes using UV-vis-NIR diffuse reflectance spectroscopy. Geoderma ,137, 70-82.

Viscarra Rossel, R. A., Cattle, S.R., Ortega, A., and Fouad, Y. (2009). In situ measurement of soil colour, mineral composition and clay content by vis-NIR spectroscopy. Geoderma, $150,253-266$.

Vohland, M., Ludwig, M., Thiele-Bruhn, S., and Ludwig, B. (2014). Determination of soil properties with visible to near- and mid-infrared spectroscopy: Effects of spectral variable selection. Geoderma, 223-225, 88-96.

Wang, D., Chakraborty, S., Weindorf, D.C., Li, B., Sharma, A., Paul, S., and Ali, N. (2015). Geoderma Synthesized use of VisNIR DRS and PXRF for soil characterization : Total carbon and total nitrogen. Geoderma ,243-244, 157-167.

Wang, Z., and Fingas, M. (1995). Differentiation of the source of spilled oil and monitoring of the oil weathering process using gas chromatography-mass spectrometry. $J$. Chromatogr A, 712 (2), 321-343.

Wartini, Ng., Brendan, P.M., and Budiman, M. (2017). Rapid assessment of petroleumcontaminated soils with infrared spectroscopy. Geoderma 289, 150-160.

Weindorf, D.C., Bakr, N., and Zhu, Y. (2014). Advances in portable X-ray fluorescence (PXRF) for environmental, pedological, and agronomic applications. Adv. Agron., 128, $1-45$.

Weisman, W. (1998). Analysis of petroleum hydrocarbons in environmental media. In: W. Weisman (Editor). Total Petroleum Hydrocarbon Criteria Working Group (TPHCWG) Series. Amherst Sci. Publ. Amherst, MA 1-98. 
Webster, G.T., Soriona-Disla, J.M., Kirk, J., Janik, L.J., Forester, S.T., McLaughlin, M.J., and Stewart, R.J. (2016). Rapid prediction of total petroleum hydrocarbons in soil using a handheld mid-infrared instrument. Talanta 160, 410-416.

Whittaker, M., Pollard, S.J.T., and Fallick, T.E. (1995). Characterisation of refractory wastes at heavy oil-contaminated sites: A review of conventional and novel analytical methods. Environ. Technol., 16, 1009-1033.

Yang, C., Wang, Z.D., Hollebone, B., Brown, C.E., Yang, Z.Y., Landriault, M. (2015). Chapter 5: Chromatographic fingerprinting analysis of crude oil and petroleum products. In: Fingas, M. (Ed.), Handbook of Oil Spill Science and Technology. John Wiley \& Sons, Inc, Hoboken, NJ, pp. 95-163

Zhang, Y., Zhu, Y.G., Houot, S., Qiao, M., Nunan, N., and Garnier, P. (2011). Remediation of polycyclic aromatic hydrocarbon (PAH) contaminated soil through composting with fresh organic wastes. Environmental Science and Pollution Research, DOI 10. 1007/s11356-011-0521-5.

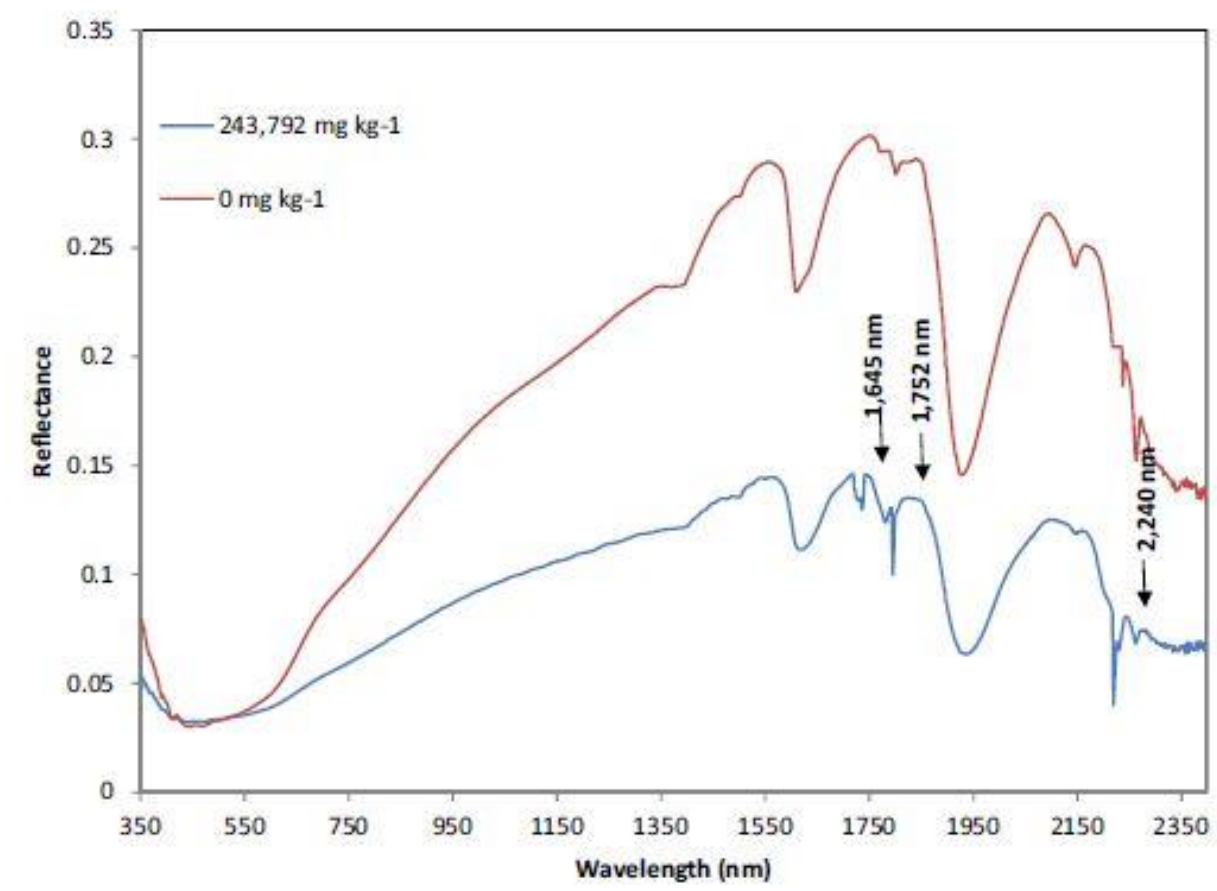

Figure 1. Visible and near infrared (vis-NIR) average reflectance for hydrocarbon contaminated (blue spectrum) and non-contaminated (red spectrum) soils (Chakraborty et al., 2015). 


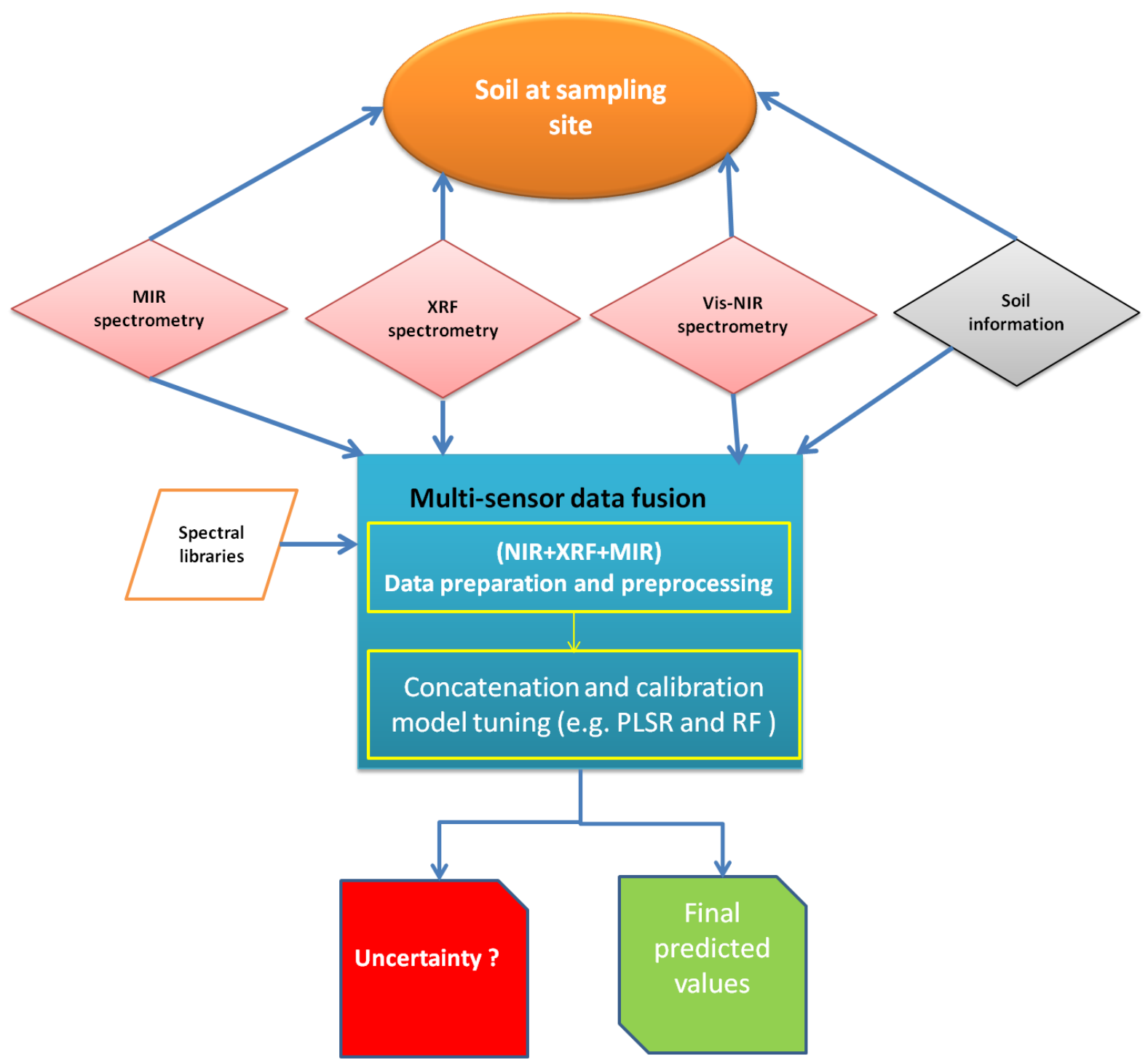

Figure 2. The integrated concept of multi-sensor data fusion for the measurement of petroleum hydrocarbon PHCs) contamination in soils and sediments. 
Table 1. Most common chromatographic and spectroscopic techniques for determining petroleum hydrocarbon contaminants (PHCs) in soil and sediment samples.

\begin{tabular}{|c|c|c|c|c|c|c|c|c|}
\hline Technique & $\begin{array}{l}\text { Targeted } \\
\text { analytes }\end{array}$ & $\begin{array}{l}\text { Sample } \\
\text { matrix }\end{array}$ & $\begin{array}{c}\text { Sample* } \\
\text { preparatio } \\
\mathbf{n}\end{array}$ & $\begin{array}{l}\text { Measuremen } \\
\text { t scale }\end{array}$ & Limit of detection & Advantages & Limitations & Reference \\
\hline GC-MS & TPHs, PAHs & $\begin{array}{l}\text { Sedimen } \\
\mathrm{t} \text { and soil }\end{array}$ & $\begin{array}{l}\text { Either air or } \\
\text { chemically } \\
\text { dried } \\
\text { samples } \\
\text { SPME } \\
\text { extraction } \\
\text { using } \\
\text { hexane } \\
\text { and/or } \\
\text { DCM, or } \\
\text { acetone } \\
\text { followed by } \\
\text { Hex:DCM } \\
\text { (1:1); } \\
\text { use silica } \\
\text { gel, florisil } \\
\text { or alumina } \\
\text { to clean up } \\
\text { extract. }\end{array}$ & Laboratory & $\begin{array}{l}1.0 \mu \mathrm{g} / \mathrm{kg} \text { for } \\
\text { individual PAH } \\
1.5 \mu \mathrm{g} / \mathrm{kg} \\
\text { Benzo(a)anthracen } \\
\text { e in sediment } \\
\mathrm{TPH}=50 \mathrm{mg} / \mathrm{kg} \text { in } \\
\text { soil }\end{array}$ & $\begin{array}{l}\text { Relatively } \\
\text { sensitive and } \\
\text { specific to } \\
\text { quantify PAHs, } \\
\text { Assess } \\
\text { sediment } \\
\text { quality for total } \\
\text { PAHs, } \\
\text { Detect } \\
\text { signatures of } \\
\text { priority PAHs } \\
\text { in sediments. }\end{array}$ & $\begin{array}{l}\text { Untimely, } \\
\text { high-labour } \\
\text { sampling } \\
\text { demanded, } \\
\text { Uneconomic } \\
\text { in assessing } \\
\text { large-scale } \\
\text { contamination } \\
\text { Use toxic } \\
\text { solvent for } \\
\text { extraction } \\
\text { purposes (e.g., } \\
\text { Soxhlet), } \\
\text { Suitable for } \\
\text { thermally } \\
\text { stable } \\
\text { analytes, } \\
\text { Costly and } \\
\text { time } \\
\text { consuming } \\
\text { analysis }\end{array}$ & $\begin{array}{l}\text { Wang and } \\
\text { Fingas, } \\
\text { 1995; } \\
\text { Brassingto } \\
\text { n et } \\
\text { al.,2010; } \\
\text { Poster et } \\
\text { al., 2006; } \\
\text { Okparanma } \\
\text { and } \\
\text { Mouazen, } \\
\text { 2013; } \\
\text { Chimezie } \\
\text { et al. 2005 } \\
\text { Risdon et } \\
\text { al., 2004 }\end{array}$ \\
\hline GC-FID & TPHs, PAHs & Soil & $\begin{array}{l}\text { Dry sample } \\
\text { either in an } \\
\text { oven at } \\
105^{\circ} \mathrm{C} \text { or } \\
\text { chemically } \\
\text { using } \\
\text { anhydrous } \\
\mathrm{Na}_{2} \mathrm{SO}_{4} \text {, }\end{array}$ & Laboratory & $\begin{array}{l}\mathrm{TPH}=10 \mathrm{mg} / \mathrm{kg} \text { in } \\
\text { soil } \\
\mathrm{PAH}=330 \mu \mathrm{g} / \mathrm{kg} \\
\text { in soil, TPH =2.30 } \\
\mathrm{mg} / \mathrm{kg} \text { in } \\
\text { soil/sediment } \\
\text { matrix }\end{array}$ & $\begin{array}{l}\text { Simple, } \\
\text { Detect wide } \\
\text { Measure array } \\
\text { of hydrocarbon } \\
\text { compounds, } \\
\text { Sensitive and } \\
\text { selective, } \\
\text { Applied both }\end{array}$ & $\begin{array}{l}\text { Costly and } \\
\text { time } \\
\text { consuming } \\
\text { analysis, } \\
\text { Instrument } \\
\text { calibration } \\
\text { difficulties, } \\
\text { Effect of }\end{array}$ & $\begin{array}{l}\text { Brassingto } \\
\text { n et } \\
\text { al.,2010; } \\
\text { TPHCWG, } \\
\text { 1998; } \\
\text { Vallejo et } \\
\text { al., 2001; } \\
\text { Cortes et }\end{array}$ \\
\hline
\end{tabular}




\begin{tabular}{|c|c|c|c|c|c|c|c|c|}
\hline Technique & $\begin{array}{l}\text { Targeted } \\
\text { analytes }\end{array}$ & $\begin{array}{l}\text { Sample } \\
\text { matrix }\end{array}$ & $\begin{array}{c}\text { Sample* } \\
\text { preparatio } \\
\text { n } \\
\end{array}$ & $\begin{array}{c}\text { Measuremen } \\
\text { t scale }\end{array}$ & Limit of detection & Advantages & Limitations & Reference \\
\hline & & & $\begin{array}{l}\text { extract } \\
\text { sample } \\
\text { using } \\
\text { hexane and } \\
\text { DCM, use } \\
\text { silica gel or } \\
\text { alumina to } \\
\text { clean up } \\
\text { extract. }\end{array}$ & & & $\begin{array}{l}\text { qualitatively } \\
\text { and } \\
\text { quantitatively. }\end{array}$ & $\begin{array}{l}\text { sample } \\
\text { matrix, } \\
\text { Suitable for } \\
\text { thermally } \\
\text { stable } \\
\text { analytes }\end{array}$ & al., 2012 \\
\hline $\begin{array}{l}\text { Vis-NIR } \\
\text { spectroscopy }\end{array}$ & TPHs, PAHs & $\begin{array}{l}\text { Soil and } \\
\text { sediment }\end{array}$ & $\begin{array}{l}\text { Air dry } \\
\text { sample, } \\
\text { crush and } \\
\text { sieve to } \\
\text { remove } \\
\text { stones and } \\
\text { plant } \\
\text { residues. } \\
\text { Field level: } \\
\text { no sample } \\
\text { preparation. }\end{array}$ & $\begin{array}{l}\text { Laboratory } \\
\text { and field }\end{array}$ & NA & $\begin{array}{l}\text { Rapid, simple, } \\
\text { inexpensive, } \\
\text { Expedited site } \\
\text { investigation, } \\
\text { No prior site } \\
\text { investigation } \\
\text { Portable }\end{array}$ & $\begin{array}{l}\text { Relatively fair } \\
\text { accuracy, } \\
\text { Affected by } \\
\text { moisture } \\
\text { content, } \\
\text { Does not } \\
\text { measure TPH } \\
\text { directly hence } \\
\text { has no LOD. }\end{array}$ & $\begin{array}{l}\text { Deeks et } \\
\text { al., } 2014 \\
\text { Okparanma } \\
\text { et al., } \\
2014 \mathrm{~b}\end{array}$ \\
\hline MIRS & TPH & Soil & $\begin{array}{l}\text { Air dry } \\
\text { sample and } \\
\text { sieve }\end{array}$ & $\begin{array}{l}\text { Laboratory } \\
\text { and field }\end{array}$ & NA & $\begin{array}{l}\text { Excellent } \\
\text { detector for } \\
\text { hydrocarbon } \\
\text { levels. Portable }\end{array}$ & $\begin{array}{l}\text { Affected by } \\
\text { moisture } \\
\text { content, } \\
\text { Does not } \\
\text { measure TPH } \\
\text { directly hence } \\
\text { has no LOD. }\end{array}$ & $\begin{array}{l}\text { Horta et } \\
\text { al., 2015; } \\
\text { Sorak et } \\
\text { al., } 2012\end{array}$ \\
\hline $\begin{array}{l}\text { Portable Field } \\
\text { gas } \\
\text { chromatograph } \\
\text { y }\end{array}$ & $\begin{array}{l}\text { Volatile and } \\
\text { semi-volatile } \\
\text { hydrocarbon } \\
\text { s including } \\
\text { TPHs PAHs }\end{array}$ & $\begin{array}{l}\text { Soil, } \\
\text { soil-gas }\end{array}$ & - & Field & ${ }^{\mathrm{a}} 1-10 \mathrm{mg} / \mathrm{kg}$ in soil & $\begin{array}{l}\text { Portable, } \\
\text { lightweight, } \\
\text { compact, } \\
\text { durable, highest } \\
\text { quality amongst }\end{array}$ & $\begin{array}{l}\text { Expensive } \\
\text { due to the 'fit } \\
\text { for purpose' } \\
\text { gas carrier }\end{array}$ & $\begin{array}{l}\text { Harris, } \\
2003\end{array}$ \\
\hline
\end{tabular}




\begin{tabular}{|c|c|c|c|c|c|c|c|c|}
\hline Technique & $\begin{array}{c}\text { Targeted } \\
\text { analytes }\end{array}$ & $\begin{array}{c}\text { Sample } \\
\text { matrix }\end{array}$ & $\begin{array}{c}\text { Sample* } \\
\text { preparatio } \\
\text { n }\end{array}$ & $\begin{array}{c}\text { Measuremen } \\
\text { t scale }\end{array}$ & Limit of detection & Advantages & Limitations & Reference \\
\hline & & & & & & $\begin{array}{l}\text { other analytical } \\
\text { techniques }\end{array}$ & & \\
\hline Immunoassay & PAHs, & Soil & - & Field & $\begin{array}{l}\mathrm{TPH}=10-50 \\
\mathrm{mg} / \mathrm{kg} \text { in soil }\end{array}$ & $\begin{array}{l}\text { Portable, quick, } \\
\text { sensitive, } \\
\text { economic, } \\
\text { It complements } \\
\text { chromatograph } \\
\text { y procedures }\end{array}$ & $\begin{array}{l}\text { Less affinity } \\
\text { for } \\
\text { hydrocarbons } \\
\text { with rising } \\
\text { soil clay } \\
\text { content, } \\
\text { Soil matrix } \\
\text { effects }\end{array}$ & $\begin{array}{l}\text { TPHCWG, } \\
\text { 1998; } \\
\text { Weisman, } \\
1998\end{array}$ \\
\hline
\end{tabular}

* There is no single, generic protocol for the analysis of hydrocarbons by GC. The methods vary considerably depending on the nature of the sample and the goals of the analysis. Readers are referred to the references provided for additional information on the extraction method. MIRS= mid-infrared spectroscopy, $\mathrm{PXRF}=$ portable $\mathrm{X}$-ray fluorescence, $\mathrm{TPH}=$ total petroleum hydrocarbon, $\mathrm{PAH}=$ polycyclic aromatic hydrocarbon, NA=not available, GC-MS= Gas chromatography mass spectrometry, GC-FID= Gas chromatography coupled to flame ionization

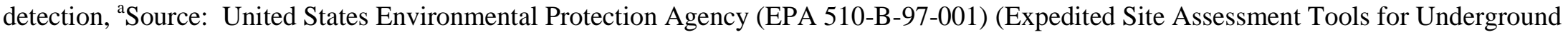
Storage Tank Sites. A Guide for Regulators. 
Table 2. Analytical techniques, multivariate analysis and machine learning results for the measurement of petroleum hydrocarbon contamination in soils and sediments.

\begin{tabular}{|c|c|c|c|c|c|c|c|}
\hline Technique & $\begin{array}{l}\text { Targeted } \\
\text { analytes }\end{array}$ & $\begin{array}{l}\text { Number } \\
\text { of samples }\end{array}$ & $\begin{array}{l}\text { Spectral range, } \\
(\mathbf{n m})\end{array}$ & $\begin{array}{l}\text { Modelling } \\
\text { technique }\end{array}$ & Statistical parameters & $\begin{array}{l}\text { Sample } \\
\text { origin }\end{array}$ & References \\
\hline Vis-NIR DRS & TPH & 46 & $350-2500$ & $\begin{array}{l}\text { PLSR } \\
\text { BRT }\end{array}$ & $\begin{aligned} & \mathrm{R}^{2}=0.79, \mathrm{RPD}= 1.64, \mathrm{RMSEP}=0.353 \\
& \mathrm{mg} / \mathrm{kg} \\
& \mathrm{R}^{2}=0.38, \mathrm{RPD}= 1.38, \mathrm{RMSEP}=0.42 \\
& \mathrm{mg} / \mathrm{kg}\end{aligned}$ & USA & $\begin{array}{l}\text { Chakraborty } \\
\text { et al., } 2010\end{array}$ \\
\hline Vis-NIR DRS & PAH & 150 & $350-2500$ & PLS & $\begin{array}{c}\mathrm{R}^{2}=0.89, \mathrm{RPD}=2.75, \mathrm{RMSEP}= \\
0.2010 \mathrm{mg} / \mathrm{kg}\end{array}$ & UK & $\begin{array}{l}\text { Okparanma } \\
\text { and } \\
\text { Mouazen, } \\
2012\end{array}$ \\
\hline Vis-NIR DRS & PAH & 150 & $350-2500$ & PLSR & $\begin{array}{c}\mathrm{R}^{2}=0.75-0.83, \mathrm{RPD}=2.0-2.32, \mathrm{RMSEP} \\
=0.21-0.25 \mathrm{mg} / \mathrm{kg}\end{array}$ & UK & $\begin{array}{l}\text { Okparanma } \\
\text { and } \\
\text { Mouazen, } \\
2013\end{array}$ \\
\hline Vis-NIR DRS & PAH & 137 & $350-2500$ & & $\begin{array}{c}\mathrm{R}^{2}=0.77-0.89, \mathrm{RPD}=1.86-3.12 \\
\mathrm{RMSEP}=1.16-1.95 \mathrm{mg} / \mathrm{kg}\end{array}$ & Nigeria & $\begin{array}{l}\text { Okparanma } \\
\text { et al., } 2014 \mathrm{a}\end{array}$ \\
\hline Vis-NIR DRS & TPH & 108 & $350-2500$ & $\begin{array}{l}\text { RFR } \\
\text { PSR } \\
\text { PLSR }\end{array}$ & $\begin{array}{l}\mathrm{RPD}=1.64 \\
\mathrm{RPD}=1.86 \\
\mathrm{RPD}=1.96\end{array}$ & USA & $\begin{array}{l}\text { Chakraborty } \\
\text { et al., } 2015\end{array}$ \\
\hline $\begin{array}{l}\text { PXRF+Vis- } \\
\text { NIR DRS }\end{array}$ & TPH & 108 & $350-2500$ & PSR & $\mathrm{R}^{2}=0.78, \mathrm{RPD}=2.19$ & USA & $\begin{array}{l}\text { Chakraborty } \\
\text { et al., } 2015\end{array}$ \\
\hline
\end{tabular}




\begin{tabular}{|c|c|c|c|c|c|c|c|}
\hline Technique & $\begin{array}{l}\text { Targeted } \\
\text { analytes }\end{array}$ & $\begin{array}{c}\text { Number } \\
\text { of samples }\end{array}$ & $\begin{array}{l}\text { Spectral range, } \\
(\mathbf{n m})\end{array}$ & $\begin{array}{l}\text { Modelling } \\
\text { technique }\end{array}$ & Statistical parameters & $\begin{array}{c}\text { Sample } \\
\text { origin }\end{array}$ & References \\
\hline MIR & TPH & 205 & $2170-3330$ & PLSCV & $\mathrm{RMSE}<1000 \mathrm{mg} / \mathrm{kg}$ for $0-15000 \mathrm{mg} / \mathrm{kg}$ & $\begin{array}{c}\text { Not } \\
\text { stated }\end{array}$ & $\begin{array}{c}\text { Forrester et } \\
\text { al., } 2013\end{array}$ \\
\hline MIR & TPH & 67 & & PLSR & $\mathrm{R}^{2}=0.99, \mathrm{RMSE}<200 \mathrm{mg} / \mathrm{kg}$ & Australia & $\begin{array}{l}\text { Webster et } \\
\text { al., } 2016\end{array}$ \\
\hline GC-MS & PAH & 150 & Not applicable & PLSR & $\begin{array}{c}\mathrm{R}_{\mathrm{P}}^{2}=0.89, \mathrm{RPD}: 1.52-2.79, \\
\mathrm{RMSE}=0.201 \mathrm{mg} / \mathrm{kg}\end{array}$ & & $\begin{array}{l}\text { Osborne et } \\
\text { al., } 1993\end{array}$ \\
\hline GC-FID & TPH & 26 & Not applicable & Stepwise MLR & $\begin{array}{l}\mathrm{R}_{\mathrm{P}}^{2}: 0.68-0.72 \\
\mathrm{RPD}: 0.84-1.00\end{array}$ & & $\begin{array}{l}\text { Malley et al., } \\
1999\end{array}$ \\
\hline FTIR & TPH & 172 & $400-2500$ & PLSR & $\begin{array}{c}\mathrm{R}^{2} \mathrm{cv}=0.81 \\
\mathrm{RMSECV}=4,500-8000 \mathrm{mg} / \mathrm{kg}\end{array}$ & $\begin{array}{c}\text { Not } \\
\text { stated }\end{array}$ & $\begin{array}{l}\text { Forester et } \\
\text { al., } 2010\end{array}$ \\
\hline FTIR & PAH & 65 & $350-2500$ & OLR & $\begin{array}{c}\text { Accuracy }(65.90 .25 \%), \text { FPR }(0.57-0.91) \\
\text { FNR }(0.03-0.13)\end{array}$ & Wales & $\begin{array}{l}\text { Bray et al., } \\
2010\end{array}$ \\
\hline
\end{tabular}

Vis-NIR DRS=visible and near-infrared diffuse reflectance spectroscopy, PXRF=portable x-ray fluorescence, MIR= mid-infrared, GC-MS= gas chromatography-mass spectrometry, GC-FID= gas chromatography-flame ionization detector, PLSR= partial least squares regression, PLSCV= partial least squares cross-validation, ANN= artificial neural network, $\mathrm{PSR}=$ penalized spline regression, $\mathrm{RFR}=$ random forest regression, $\mathrm{BRT}=$ boosted regression tree, $\mathrm{MLR}=$ multiple linear regression, $\mathrm{R}=$ coefficient of determination, $\mathrm{RPD}=$ residual prediction deviation, $\mathrm{RMSEP}=$ root mean square error of prediction, $\mathrm{TPH}=$ total petroleum hydrocarbon, $\mathrm{PAH}=$ polycyclic aromatic hydrocarbon, GEMAS=geochemical mapping of agricultural soils and grazing land of Europe, FTIR= Fourier transform infrared spectroscopy, OLR=ordinal logistic regression, FPR=false-positive rate, FNR=false-negative rate 
1 Table 3. Comparison of data fusion approach and performance for targeted analytes in soil

\begin{tabular}{|c|c|c|c|c|c|}
\hline Technique & $\begin{array}{l}\text { Targeted } \\
\text { analytes }\end{array}$ & $\begin{array}{l}\text { Multivariate } \\
\text { technique }\end{array}$ & $\begin{array}{l}\text { Sample } \\
\text { matrix }\end{array}$ & $\begin{array}{l}\text { Statistical } \\
\text { parameters }\end{array}$ & Reference \\
\hline Vis-NIRS & TPH & PSR & Soil & $\begin{array}{l}\mathrm{R}^{2}=0.70 \\
\mathrm{RMSE}=0.75 \\
\mathrm{RPD}=1.86\end{array}$ & \multirow{3}{*}{$\begin{array}{c}\text { Chakraborty et } \\
\text { al., } 2015\end{array}$} \\
\hline Vis-NIRS + XRF & TPH & PSR & Soil & $\begin{array}{l}\mathrm{R}^{2}=0.73 \\
\mathrm{RMSE}=0.59 \\
\mathrm{RPD}=1.96\end{array}$ & \\
\hline Vis-NIRS + XRF & TPH & PSR +RFR & Soil & $\begin{array}{l}\mathrm{R}^{2}=0.78, \\
\mathrm{RMSE}=0.53, \\
\mathrm{RPD}=2.19\end{array}$ & \\
\hline $\mathrm{XRF}$ & $\mathrm{TN}$ & RFR & Soil & $\begin{array}{l}\mathrm{R}^{2}=0.9 \\
\mathrm{RMSEP}=0.02 \\
\mathrm{RPD}=3.20\end{array}$ & \multirow{6}{*}{$\begin{array}{l}\text { Wang et al., } \\
2015\end{array}$} \\
\hline $\mathrm{XRF}$ & $\mathrm{TC}$ & RFR & Soil & $\begin{array}{l}\mathrm{R}^{2}=0.77 \\
\mathrm{RMSE}=0.336 \\
\mathrm{RPD}=2.11\end{array}$ & \\
\hline Vis-NIRS & $\mathrm{TN}$ & RFR & Soil & $\begin{array}{l}\mathrm{R}^{2}=0.90 \\
\mathrm{RMSE}=0.019 \\
\mathrm{RPD}=3.23\end{array}$ & \\
\hline Vis-NIRS & $\mathrm{TC}$ & RFR & Soil & $\begin{array}{l}\mathrm{R}^{2}=0.81 \\
\mathrm{RMSE}=0.331 \\
\mathrm{RPD}=2.33\end{array}$ & \\
\hline Vis_NIRS+PXRF & $\mathrm{TN}$ & RFR & Soil & $\begin{array}{l}\mathrm{R}^{2}=0.91 \\
\mathrm{RMSE}=0.019 \\
\mathrm{RPD}=3.39\end{array}$ & \\
\hline Vis-NIRS+PXRF & $\mathrm{TC}$ & RFR & Soil & $\begin{array}{l}\mathrm{R}^{2}=0.83 \\
\mathrm{RMSE}=0.319, \\
\mathrm{RPD}=2.42\end{array}$ & \\
\hline
\end{tabular}

$2 \overline{\mathbf{R}}=$ coefficient of determination, $\mathbf{R P D}=$ residual prediction deviation, $\mathbf{R M S E}=$ root mean 3 square error, RMSEP = root mean square error of prediction, $\mathbf{P S R}=$ penalised spline 4 regression, $\mathbf{R F R}=$ random forest regression, Vis-NIRS=visible and near infrared 5 spectroscopy, $\mathbf{X R F}=\mathrm{X}$-ray fluorescence, $\mathbf{T N}=$ total nitrogen, $\mathbf{T C}=$ total carbon, $\mathbf{T P H}=$ 6 total petroleum hydrocarbon. 
9 Table 4. Factors influencing decision in selecting analytical techniques

\begin{tabular}{|c|c|c|c|c|}
\hline Technique & $\begin{array}{l}\text { Analysis run } \\
\text { time (min) }\end{array}$ & $\begin{array}{l}\text { Analysis cost per } \\
\text { sample }\end{array}$ & $\begin{array}{c}\text { Expertise } \\
\text { needed }\end{array}$ & Limitations \\
\hline $\begin{array}{l}\text { Headspace analysis: } \\
\text { PIDs }\end{array}$ & ${ }^{\mathrm{a}} 1-30$ & ${ }^{a} f_{0.69-6.89}$ & L-M & $\begin{array}{l}\text { Less sensitive to detect } \\
\text { aromatic hydrocarbons, High } \\
\text { amount of organic content can } \\
\text { affect the measurements }\end{array}$ \\
\hline $\begin{array}{l}\text { Headspace analysis: } \\
\text { FIDs }\end{array}$ & ${ }^{\mathrm{a}} 1-30$ & a $0.69-£ 6.89$ & L-M & $\begin{array}{l}\text { Less sensitive to aliphatic } \\
\text { hydrocarbons, High organic } \\
\text { content can affect the } \\
\text { measurements }\end{array}$ \\
\hline $\begin{array}{l}\text { Field Gas } \\
\text { Chromatographs }\end{array}$ & ${ }^{\mathrm{a}} 10-60$ & a£13.78 - £48.22 & M-H & A skilled operator is needed \\
\hline Portable GC/MS: & ${ }^{b} 10$ & na & M-H & $\begin{array}{l}\text { A skilled operator is needed, } \\
\text { Requires prior sample } \\
\text { extraction, on-site carrier gas, } \\
\text { Insensitivity issues, } \\
\text { particularly microchip GCs }\end{array}$ \\
\hline $\begin{array}{l}\text { Vis-NIR } \\
\text { Spectrophotometer }\end{array}$ & na & na & M-H & $\begin{array}{l}\text { Comparable accuracy for } \\
\text { heavy metals and hydrocarbon }\end{array}$ \\
\hline $\begin{array}{l}\text { Portable x-ray } \\
\text { fluorescence }\end{array}$ & $30 s-2 \min$ & na & M-H & A skilled operator is needed \\
\hline Immunoassay test kit & a $30-45$ & ”£13.78 - £41.34 & M & $\begin{array}{l}\text { Cross-reactivity may impact } \\
\text { interpretation of result }\end{array}$ \\
\hline
\end{tabular}

10Key: $\mathbf{L}=$ low, $\mathbf{M}=$ medium, $\mathbf{H}=$ high, $\mathbf{n a}=$ not available, ${ }^{\text {a }}$ Source: United States Environmental 11 Protection Agency (EPA 510-B-97-001) (Expedited Site Assessment Tools for Underground 12 Storage Tank Sites. A Guide for Regulators, ${ }^{\mathbf{b}}$ Source: Harris (2003). 